\title{
Generic Airspace Concepts and Research
}

\author{
Richard H. Mogford, Ph.D.* \\ NASA Ames Research Center, Moffett Field, CA, 94035
}

\begin{abstract}
The purpose of this study was to evaluate methods for reducing the training and memorization required to manage air traffic in mid-term, Next Generation Air Transportation System (NexGen) airspace. We contrasted the performance of controllers using a sector information display and NextGen automation tools while working with familiar and unfamiliar sectors. The airspace included five sectors from Oakland and Salt Lake City Centers configured as a "generic center" called "West High Center." The Controller Information Tool was used to present essential information for managing these sectors. The Multi Aircraft Control System air traffic control simulator provided data link and conflict detection and resolution. There were five experienced air traffic controller participants. Each was familiar with one or two of the five sectors, but not the others. The participants rotated through all five sectors during the ten data collection runs. The results addressing workload, traffic management, and safety, as well as controller and observer comments, supported the generic sector concept. The unfamiliar sectors were comparable to the familiar sectors on all relevant measures.
\end{abstract}

\section{Nomenclature}

$M=$ mean

$S D=$ standard deviation

$t=$ Student's t-statistic

$p=$ probability

\section{Introduction}

In the current air traffic management system, sectors of airspace have unique designs, nomenclature, and associated procedures. This has evolved to accommodate navigation, traffic flow, and safety requirements. However, the result is that controllers need extensive training on sectors they manage, which can make the transfer of staff between areas or facilities difficult.

This Next Generation Air Transportation System ${ }^{1}$ (NextGen) research project focuses on exploring the concept of "generic" airspace that can be worked with less training. ${ }^{2}$ This will allow flexible allocation of human resources based on system need, less constrained by operator knowledge limitations. It will also provide a basis for dynamically reconfigurable airspace and other innovations to increase capacity. ${ }^{3,45}$ Controllers could manage a variety of sectors, adaptable airspace, or dynamic sectors as dictated by traffic requirements. A byproduct may be improved situation awareness, given fewer demands on cognitive resources. Factors that tend to create complexity in sectors, and hence workload, could also be identified and minimized.

This work builds on research completed by MITRE in 2007. ${ }^{6,7}$ A Universal High Altitude Airspace (UHAA) evaluation was conducted with 16 controllers managing four unfamiliar sectors (including one sector used in the present study). Information was provided for sector boundaries, special use airspace, sector numbers and altitudes, radio frequencies of adjacent sectors, and major navigational aids (NAVAIDS). The results supported the UHAA hypothesis that controllers could work unfamiliar, ultra-high altitude sectors in the current operational environment.

Current Federal Aviation Administration (FAA) plans for generic sectors include them as part of a Mid-term, High Altitude Airspace Concept. ${ }^{8}$ It is assumed for this concept that data link will be in use for transfer of

\footnotetext{
${ }^{*}$ Research Psychologist, Human Systems Integration Division, MS 262-4, NASA Ames Research Center, Moffett
} Fied, CA, 94035. 
communication, clearance delivery, and exchange of route information. Conflict detection and resolution (CD\&R) will also be available, and flights will follow four-dimensional trajectories (also known as Trajectory Based Operations or TBO).

\section{Background}

The intent of the generic airspace task is to create or apply sector design features, automation tools, information displays, and procedures that will enable controllers to easily adapt to changes in airspace. This could help them move between sectors or respond to alterations in sector size and shape.

For the initial phase of our work, we created a Controller Information Tool (CIT) that provided the necessary sector and traffic flow information to enable a controller to manage an unfamiliar sector. This sought to reduce the time required to learn and adapt to the sector by facilitating familiarization, rather than by changing sector characteristics. The goal was not to develop a stand-alone tool, but to present the information needed by the controller to work traffic.

Other methods for creating airspace that is easier to learn and use include modifying the sector (e.g., removing or simplifying features and data) and providing automation tools to simplify the controller's tasks. These strategies are interrelated in that automation can have the effect of reducing information needs. For example, if data link is used for transfer of communication to the next sector, the controller does not have to use adjacent sector frequencies, and these are no longer part of the sector map data that must be memorized.

For Phase 1 of this task, we developed a generic sector in Oakland Center (ZOA) airspace and used present-day automation and procedures, employing the Multi Aircraft Control System (MACS) air traffic control simulator and the CIT. For Phase 2, we expanded the airspace by adding a second sector and applied mid-term NextGen automation tools to create a future air traffic management environment. We modified the sector information based on user input and continued to provide it on a stand-alone display.

The purpose of the Phase 3 experiment reported here was to conduct a more thorough test of whether controllers can manage unfamiliar sectors with an acceptable level of workload, efficiency, and safety, in a generic airspace environment that includes NextGen automation tools and specific sector data. This phase focused on testing a "center" composed of generic sectors in an environment of data link and CD\&R. We used ZOA sectors 30, 33 and 43, and Salt Lake City Center (ZLC) sectors 42 and 45. These formed a fictitious area of sectors in a notional "West High Center,",with an altitude floor of 34,000 feet. Figure 1 shows a map of this center (which we called "ZHW") in the context of a national high altitude airspace concept being developed by the FAA.

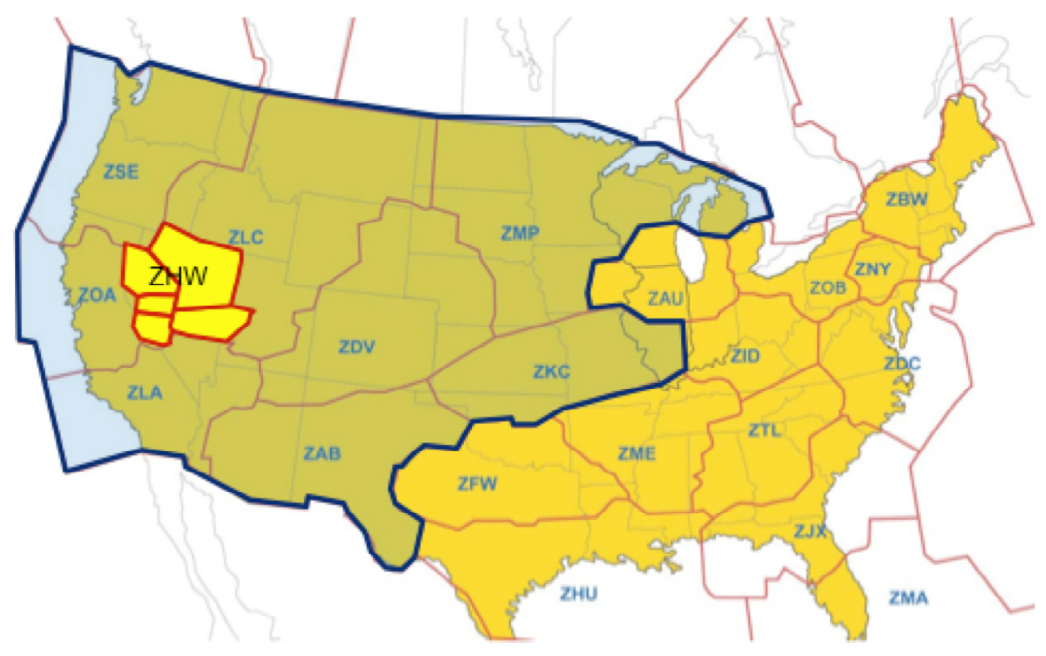

Figure 1. West High Center (ZHW) in the context of the National Airspace System and an FAA high altitude airspace concept (shaded area). 
We evaluated the generic airspace concept by rotating controllers through the five sectors. Each of the controller participants in the experiment was familiar with one or two of the sectors, but not the others, and each controller knew sectors the others did not know. This approach enabled us to test the hypothesis that generic sectors can be adequately managed by controllers who are not familiar with them. We compared data collected from the "familiar" sectors with those collected from the "unfamiliar" sectors to look for differences in workload, safety, acceptability, and other measures.

\section{Technical Approach}

\section{A. Software and Equipment}

The revised CIT showed a map of ZHW, with selectable views of each sector in a two-dimensional presentation. Information was displayed on a 30-inch monitor, mounted above the controller's main radar display. The same trackball that was used to access the radar display also controlled the CIT. (See Figure 2 for a screen image and Figure 3 for the display configuration.)

The available CIT views included:

1. Basic sector map with boundaries.

2. Sector numbers, frequencies, altitudes, and special use airspace information.

3. Locations and names of fixes and NAVAIDs.

4. Major traffic flows (showing routes, traffic direction, and exit altitudes).

The Crew-Vehicle Systems Research Facility Air Traffic Control Laboratory was used to test the generic airspace concept. Located in Building N257 at NASA Ames Research Center, this laboratory has ten air traffic control positions with FAA en route consoles and large format displays. The facility also has pseudo-pilot workstations and a communication system. It employs MACS to realistically simulate the FAA en route air traffic control Display System Replacement user interface. MACS was configured to provide controller-pilot data link communications for all clearances (with voice backup) and CD\&R (with suggested resolutions).

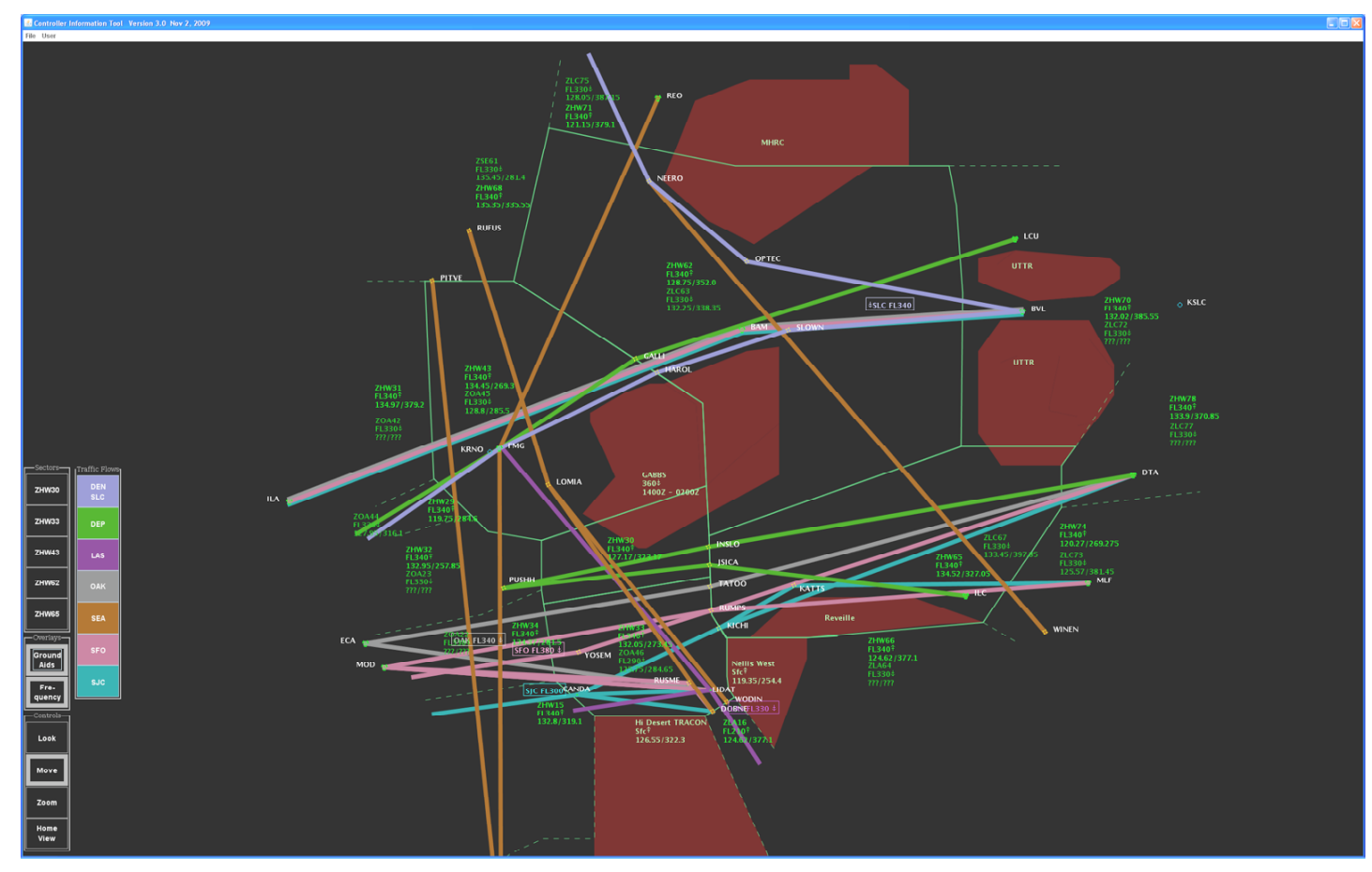

Figure 2. CIT screen for West High Center. 


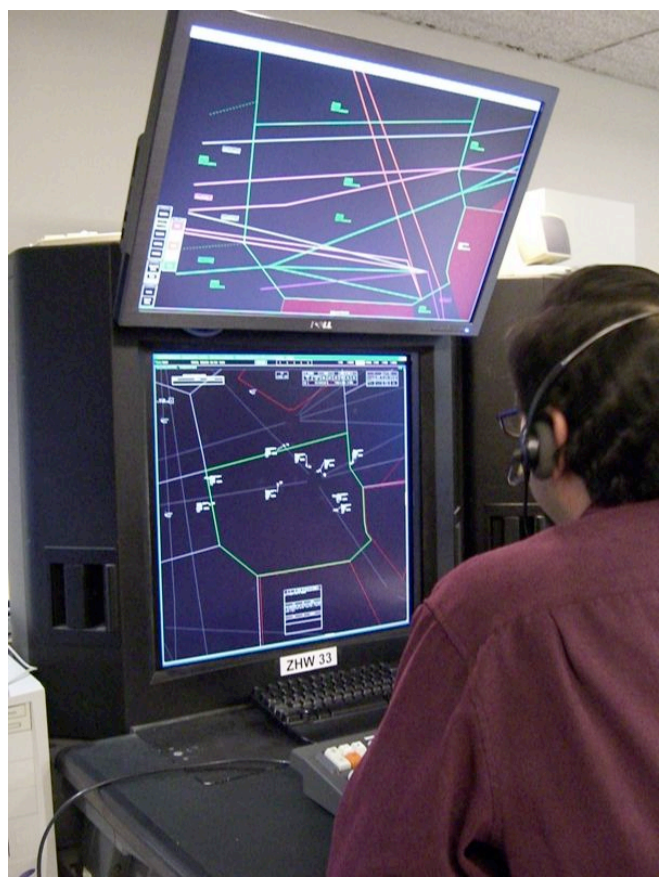

Figure 3. CIT and radar display configuration.

\section{B. Traffic Scenarios}

We created two traffic scenarios for this test, drawn from actual ZOA and ZLC flights. Traffic was run independently in each of the five sectors. Scenarios had comparable workloads and were adjusted to provide a moderate level of activity. (The same basic traffic scenario was used for each version, with changes in aircraft call signs, starting times, and positions to make them appear different.) Our goal was to design the traffic problems so that they had moderate traffic and complexity. Table 1 shows the Monitor Alert Parameter ${ }^{9}$ (MAP) values for the actual FAA sectors compared with the peak traffic counts for each scenaario. (MAP values are an estimate of the maximum capacity for the sector.) Routes were designed with the assumption that all flights were global positioning system equipped and made best use of published waypoints and Q-routes as opposed to using the ground-based jet route structure. One additional scenario was created for training.

Table 1. MAP and maximum scenario traffic values for each sector.

\begin{tabular}{|c|c|c|c|}
\hline Sector & MAP Value & Maximum & Percentage \\
\hline 30 & 13 & 11 & $77 \%$ \\
\hline 33 & 18 & 16 & $61 \%$ \\
\hline 43 & 18 & 14 & $83 \%$ \\
\hline 62 & 19 & 11 & $79 \%$ \\
\hline 65 & 23 & 13 & $57 \%$ \\
\hline
\end{tabular}

Aircraft tracks were initiated at the start of each scenario inside or outside of the sector boundaries. Traffic built to a moderate level within 20 minutes after the beginning of the scenario. Each scenario ran for 45 minutes. (See Figure 4 for the major traffic flows in the five sectors.) 


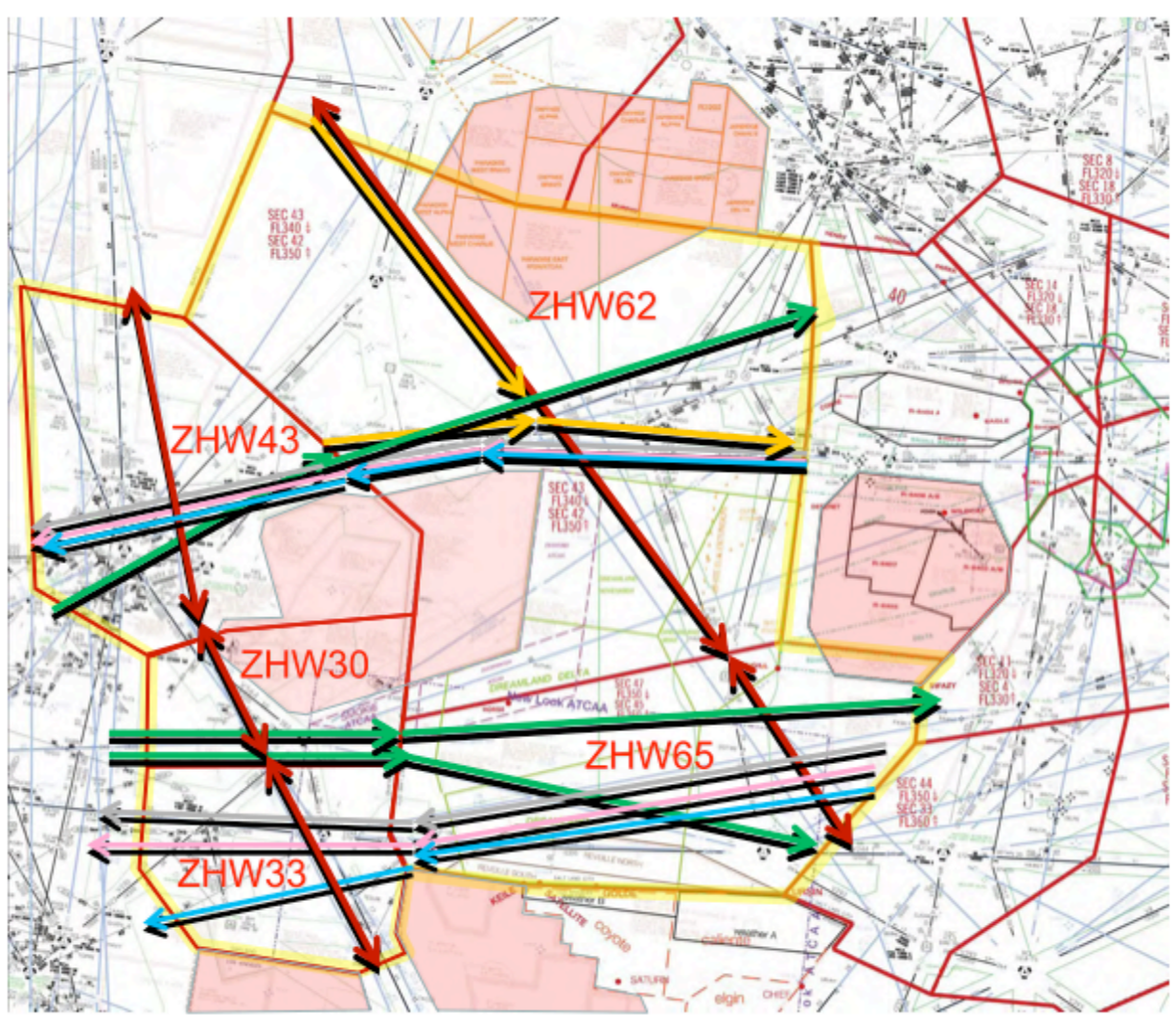

Figure 4. ZHW major traffic flows. (Sector numbers were changed for the study.)

\section{Participants}

Five recently retired (within three years) air traffic controllers acted as test subjects. While with the FAA, the controllers had worked one or two of the five sectors that were being tested, and were not familiar with the other sectors. (Please see the experimental design in Table 2 for details.) Participants had the necessary skills to manage the sectors. We used five pseudopilots and three ghost controllers to support the simulation. Five retired air traffic controllers acted as observers. All participants were paid for their time.

\section{Experimental Design}

Each controller worked one or two familiar sectors and three or four unfamiliar sectors. The order of data collection runs was counterbalanced to minimize the practice effect. (That is, if participants' performance improved over time, it would equally benefit all sectors.) The trials were separated into two groups of five runs each. This allowed us to determine if a significant practice effect occurred in the first set of five trials, compared to the second five.

\section{E. Procedures}

The study was scheduled for four days during one week (December 14 to 18, 2009). The five controller participants trained for one day, and ran traffic problems for three and one-half days. Upon arriving, they received a briefing on the study and detailed information on the automation tools in MACS. This was followed by three practice scenarios at their "home" sectors to gain experience with the tools. After that, there was an introduction to the generic airspace concept. There was no further practice prior to the data collection runs the next day.

For the first data collection run on the second day, each participant was assigned to a workstation and provided with a hands-on introduction to the CIT. They were then presented with a 45-minute traffic scenario. Then each controller rotated to a new workstation (and new sector). An expert observer followed each controller during the experiment. The participants followed the sequence of sectors in the experimental design in Table 2. 
Table 2. Experimental design for the Phase 3 Study. (The column headers have participant numbers and familiar sectors for each controller. In the body of the table, red indicates familiar sectors. There were two blocks of five trials each.)

\begin{tabular}{|c|c|c|c|c|c|}
\hline Trial & $\begin{array}{c}\text { C1 } \\
\text { (ZHW 43) }\end{array}$ & $\begin{array}{c}\text { C2 } \\
\text { (ZHW 43) }\end{array}$ & $\begin{array}{c}\text { C3 } \\
\text { (ZHW 30833) }\end{array}$ & $\begin{array}{c}\text { C4 } \\
\text { (ZHW 62) }\end{array}$ & $\begin{array}{c}\text { C5 } \\
\text { (ZHW 65) }\end{array}$ \\
\hline 1 & ZHW 30 & ZHW 33 & ZHW 43 & ZHW 62 & ZHW 65 \\
\hline 2 & ZHW 33 & ZHW 43 & ZHW 62 & ZHW 65 & ZHW 30 \\
\hline 3 & ZHW 43 & ZHW 62 & ZHW 65 & ZHW 30 & ZHW 33 \\
\hline 4 & ZHW 62 & ZHW 65 & ZHW 30 & ZHW 33 & ZHW 43 \\
\hline 5 & ZHW 65 & ZHW 30 & ZHW 33 & ZHW 43 & ZHW 62 \\
\hline 6 & ZHW 30 & ZHW 33 & ZHW 43 & ZHW 62 & ZHW 65 \\
\hline 7 & ZHW 33 & ZHW 43 & ZHW 62 & ZHW 65 & ZHW 30 \\
\hline 8 & ZHW 43 & ZHW 62 & ZHW 65 & ZHW 30 & ZHW 33 \\
\hline 9 & ZHW 62 & ZHW 65 & ZHW 30 & ZHW 33 & ZHW 43 \\
\hline 10 & ZHW 65 & ZHW 30 & ZHW 33 & ZHW 43 & ZHW 62 \\
\hline
\end{tabular}

\section{F. Data Collection}

The objective of the study was to assess differences in controller workload and other measures while working familiar versus unfamiliar sectors of generic airspace, using mid-term NextGen automation tools and the CIT. The hypothesis was that controllers would demonstrate acceptable levels of workload and other measures in unfamiliar sectors, as compared to familiar sectors.

The following is a list of the dependent measures:

1. On-screen Workload Assessment Keypad (WAK) ${ }^{10}$ input every five minutes.

2. Post-run questionnaire (workload and other measures).

3. Over-the-shoulder data collected by controller observers (including workload ratings).

4. MACS metrics (operational errors, time/distance in sector, number of data link messages).

5. Post-experiment questionnaire.

6. Frequency of access to sector data. (The CIT display timed out every 90 seconds and all key presses to access data were recorded.)

7. Post-experiment debriefing to collect additional information.

\section{Results}

This section describes the results from the analysis of the above data. Statistical tests were carried out with the data, where feasible, at the $p<.05$ level. Only the statistically significant test results are reported. Error bars on the graphs represent the standard error of the mean.

Comparisons were carried out between measures collected in the first and second blocks of trials (WAK and post-run questions). No notable or statistically significant differences were observed, and so the data for all runs were analyzed together.

\section{A. Workload}

Workload was collected from three sources: the WAK, post-run questionnaire, and observer ratings. Controller subjective judgments of workload were taken every five minutes using the WAK. A one to five scale appeared at the top of the main radar display, and the participant could use the trackball pointer or labeled keyboard keys to enter the value. A rating of one was defined to be very low workload (such as on a night shift in a low volume sector) and five was defined as maximum workload (when the controller would normally request the help of a D-side assistant). Average and peak workload were rated on a five point scale after each run on the post-run questionnaire, and observers made ratings of how hard they thought the controllers were working. Figure 5 shows the results from these three sources. These independent measures are in general agreement that the workload for unfamiliar sectors was not 
much different from that of familiar sectors. Workload was generally in the low to moderate range for all measures. One controller's ratings on the WAK and post-run questionnaire were uniformly low (mostly one out of five) and these data affected the averages, which would have otherwise been closer to the mid-range.

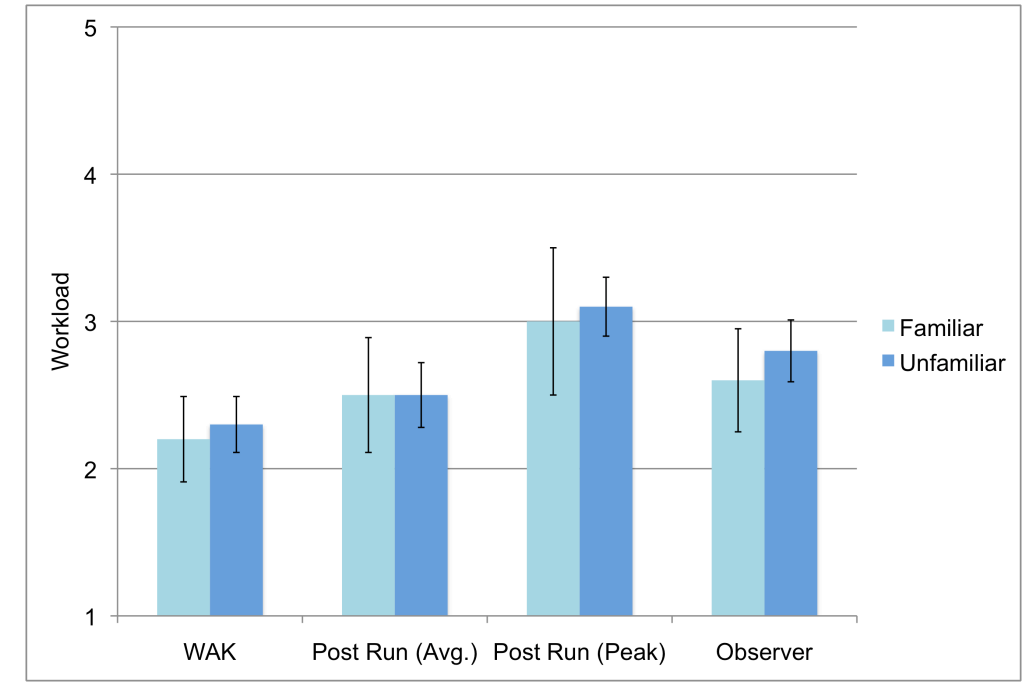

Figure 5. Comparison of workload ratings $(1=$ low workload and $5=$ high workload $)$.

\section{B. Post-run Questionnaire}

The post-run questionnaire also included items about safety, traffic management, etc. (Ratings represented the average level of agreement with the item statement with $1=$ "Strongly Disagree," 2 = "Somewhat Disagree," $3=$ "Neutral," 4 = "Somewhat Agree," and 5 = "Strongly Agree.")

Figure 6 is a summary of the post-run questionnaire data averaged for familiar and unfamiliar sectors. The average ratings on the first four scales suggest that traffic was manageable in both familiar and unfamiliar sectors, and that safety was not compromised. It appears that more familiarity with the sectors would have changed the way the controllers managed traffic. This was the only result that showed a statistically significant difference, with familiar $(M=1.8, S D=0.57)$ and unfamiliar $(M=2.8, S D=0.36), t(4)=-3.31, p=.03)$. Required information (presumably on the CIT) was also available and easy to find.

\section{MACS Metrics}

MACS data were collected for separation losses, time/distance in sector, and data link uplinks. There were nine losses of separation during the simulation, as shown in Table 3. (Several recorded conflicts were eliminated for various reasons, but we adopted a conservative approach, retaining events if there was any doubt.) We suspect that several errors were due to controllers "trying out" the conflict probe and resolution tools. When considered as a ratio of the number of runs, there was not much difference between the familiar and unfamiliar sectors. (There were 12 trials for familiar sectors and 38 trials for unfamiliar sectors.)

Table 3. Losses of separation.

\begin{tabular}{|l|c|c|}
\cline { 2 - 3 } \multicolumn{1}{c|}{} & Count & Ratio \\
\hline Familiar & 2 & 0.17 \\
\hline Unfamiliar & 7 & 0.18 \\
\hline
\end{tabular}

The differences in number of data link uplinks or time/distance flown in sector between familiar and unfamiliar sectors were small and not statistically significant. 


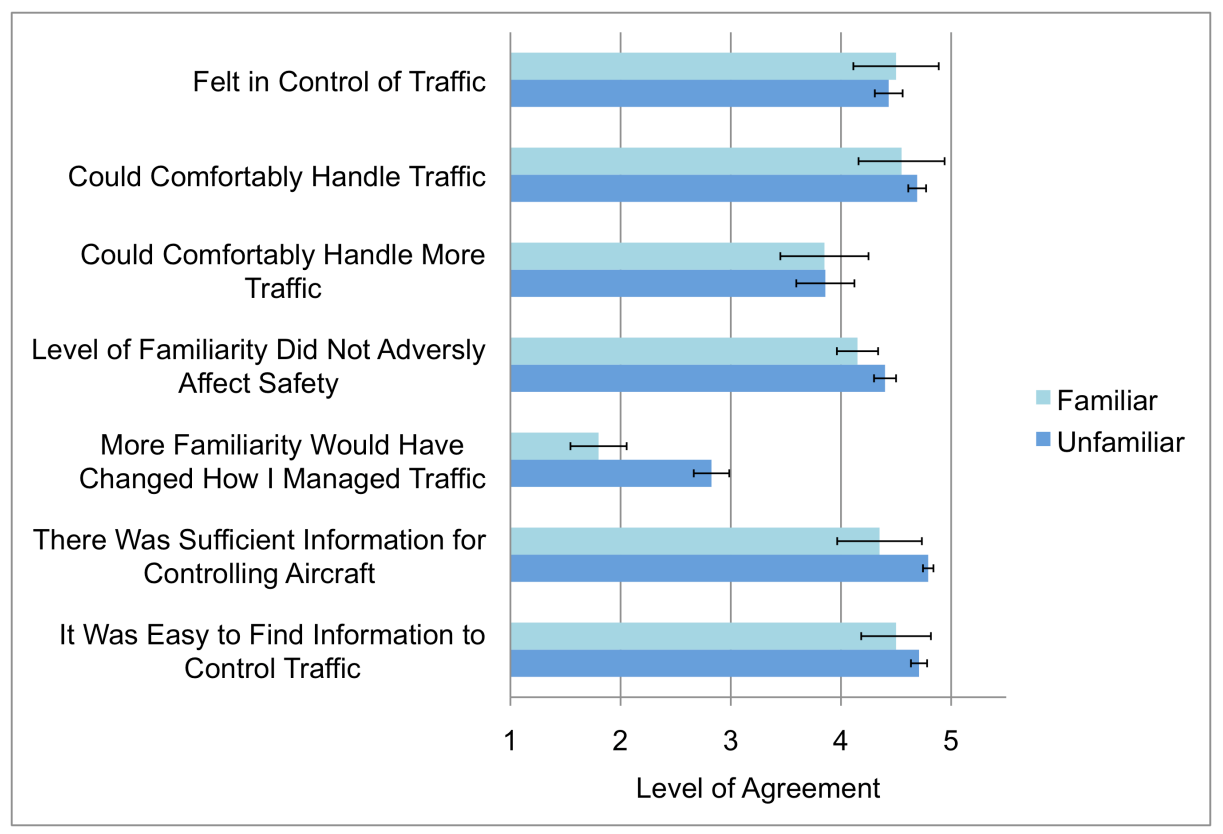

Figure 6. Summary of post-run data.

\section{Access to Sector Data}

The CIT was used to present data about the sectors. Figure 7 shows the results for how often controllers accessed three different types of sector data, using the on-screen buttons. (Sector frequencies and numbers were on the same button.) We can safely assume (based on participant feedback) that the data item being accessed in the "Frequency/Sector" category was adjacent sector number for handoffs. (Frequencies were automatically transferred to the aircraft.) Sector numbers were accessed more often for unfamiliar sectors. This difference was statistically significant, with familiar $(M=4.2, S D=3.15)$ and unfamiliar $(M=10.9, S D=4.22), t(4)=-4.41, p=.01)$. Ground aids (e.g., fixes) were not accessed very often, but somewhat more frequently for unfamiliar sectors. Route information was viewed at about the same rate for both familiar and unfamiliar sectors.

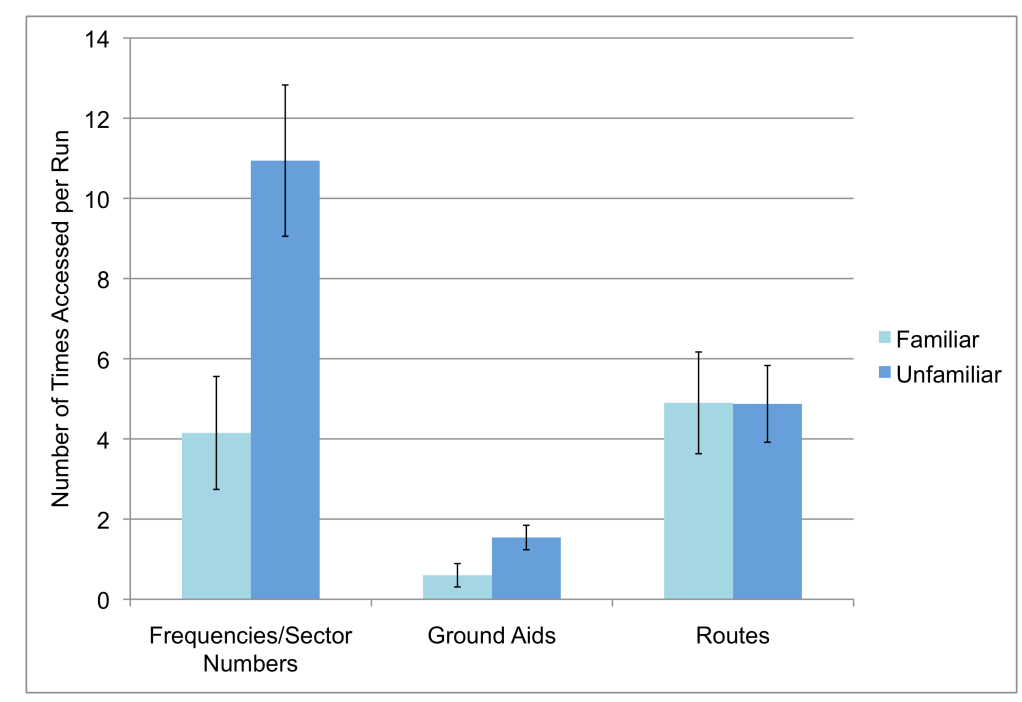

Figure 7. Average frequency of CIT usage. 


\section{E. Post-experiment Questionnaire}

This questionnaire included items about the change in familiarity for the familiar versus unfamiliar sectors. The controllers were asked how much more familiar they were with each sector after the end of the 10 simulation trials. Figure 8 shows that there was a substantial increase in familiarity with the unfamiliar sectors, but not (as would be expected) with the familiar sectors. The difference for the unfamiliar sectors is significant with familiar $(M=2.2$, $S D=1.26)$ and unfamiliar $(M=4.0, S D=0.88), t(18)=-5.49, p=.00)$.

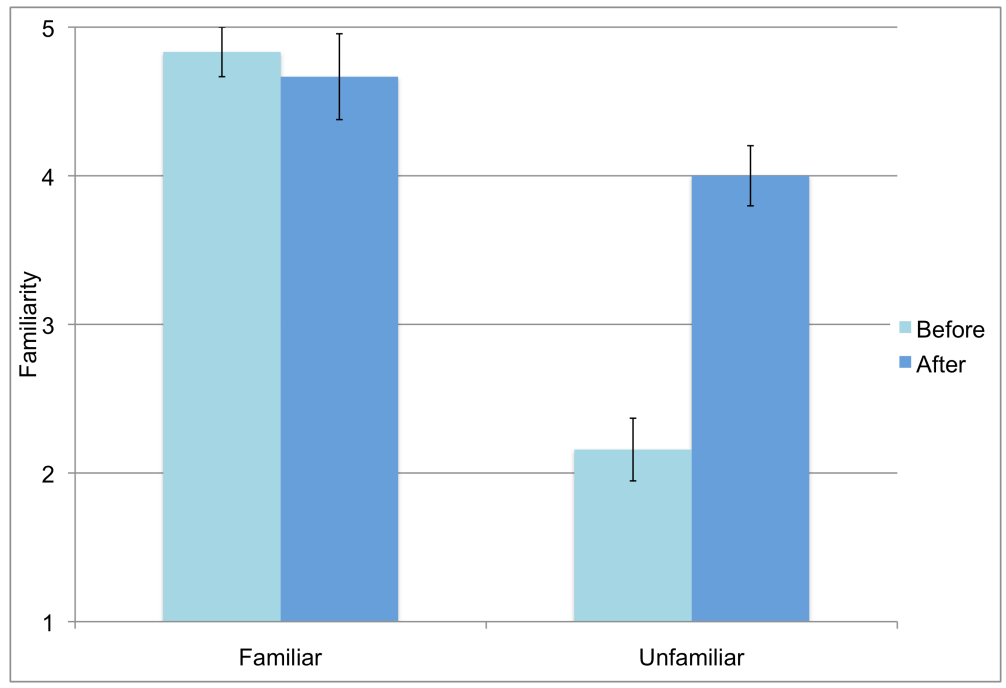

Figure 8. Average familiarity with sectors before and after the experiment.

It also appears that the CIT was useful to the participants for both kinds of sectors, as shown in Figure 9. Figure 10 includes opinions about the NextGen tools, including data link, conflict probe, and the suggested conflict resolutions. Data link and the conflict probe appear to have support, though the feedback regarding the conflict resolutions was not as positive, and there is more variation in the responses. One controller reported not using the conflict resolution capabilities at all.

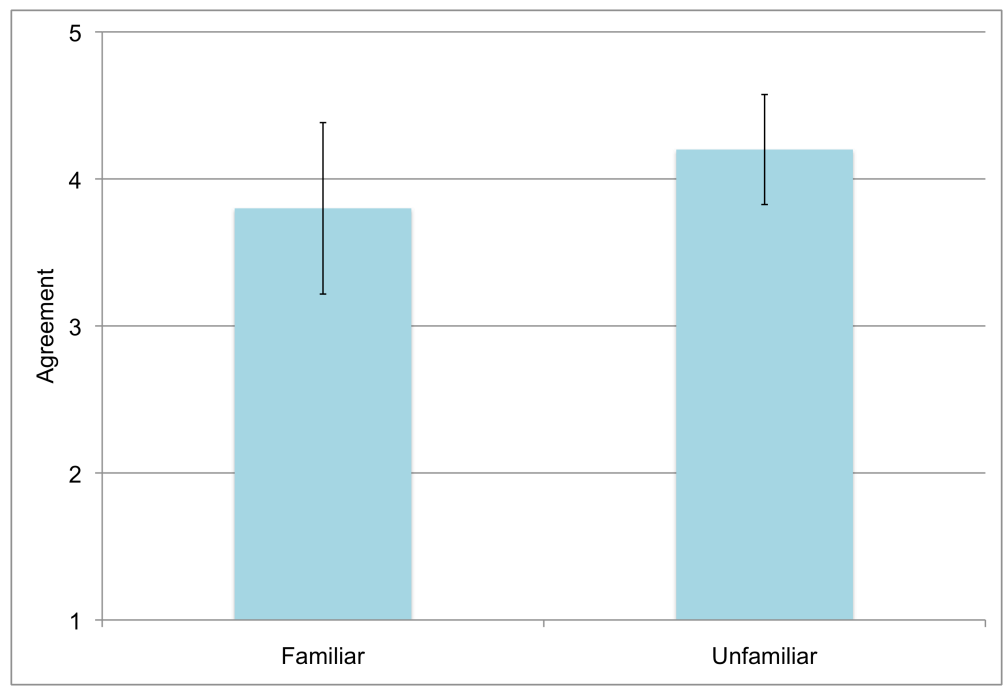

Figure 9. "The Controller Information Tool was useful in helping me to control traffic." 


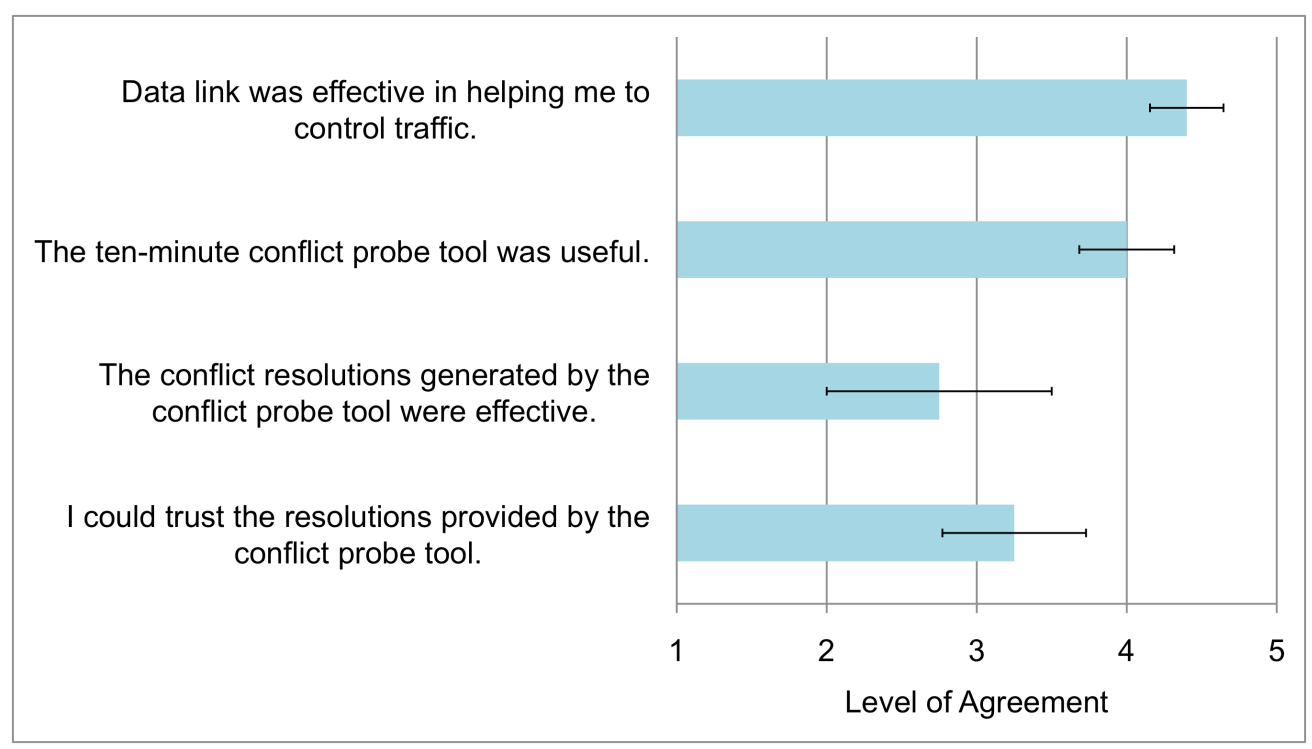

Figure 10. Average agreement ratings to questions about NextGen automation tools.

\section{F. Post-experiment Briefing}

\section{Overall Concept}

In general, the controllers supported the generic sector concept, saying it was easy to move between familiar and unfamiliar sectors. One suggested that this was smoother during the second set of five scenario runs, since there had been time to practice on the unfamiliar sectors during the first five runs. There was a comment that Sector 33 had altitude restrictions to airports and this additional complexity would make it more difficult for it to be generic. Moving between more sectors than in the current work environment might reduce complacency and help keep controllers "on their toes." There could also be job satisfaction benefits from a "change of scenery."

If controllers moved between a larger number of sectors than today, there could be a loss of "comfort level" as they started to work a less familiar sector, though the participants said the sector knowledge would come back quickly. Over time, controllers learn the "traps" in sectors. (Traps are where losses of separation may occur.) One problem working a less familiar sector might be handling emergencies. Information on nearby airports, etc., might not be readily available from memory. Under normal conditions, the controller would have time to look these things up. If more attention had to be paid to learning an unfamiliar sector, controllers might have less time to "help airplanes" with routing requests, etc.

The participants thought that all high-altitude sectors could be candidates for generic airspace. Adding a briefing prior to starting work would help with orientation to an unfamiliar sector. There was some discussion of whether new controllers should be introduced to simpler high altitude or generic airspace first. On the other hand, it might be easier for experienced controllers to move between generic sectors.

\section{NextGen Tools}

The NextGen tools (data link and CD\&R) helped the controllers to manage traffic, but the participants suggested that high altitude airspace is generally not very complex. Data link downlinks from the aircraft might augment the generic sector concept in that aircraft could initiate trajectory requests via data link. Some controllers wanted a faster data link user interface. However, others liked our "three step method" for sending data link messages, since it allowed for an "are you sure?" function. A data link history list was recommended.

Some participants found the long-range conflict probe to be helpful. However, they had suggestions about improving the alerting and user interface. Controllers also liked the "what if" capabilities of the MACS trial planner. Color coding to identify separate pairs of conflicts would be useful. 
The controllers suggested trying a conflict resolution setting of seven to nine miles so that they would have more of a buffer and would not have to watch the conflict solutions so carefully. (The setting was at the minimum of five miles for our study.) Controllers found some of the conflict resolutions to be inefficient and of limited use. Some of the resolutions did not make sense (e.g., turning an aircraft in front of the conflicting aircraft). Participants also wanted more altitude (as opposed to route) resolutions. Some way of keeping track of which conflicts had been "fixed" would be useful. The simulation pilots sometimes took a long time to respond to data link messages.

\section{Controller Information Tool}

The CIT was considered to be very helpful, but some controllers did not like the location of the screen above the main MACS display. Suggestions for improvements included adding weather information, arrival routings, simplified Letters of Agreement, a drawing tool, and low altitude boundaries. Participants said that the most useful sector information was the adjacent sector numbers, followed by the fixes and NAVAIDs. The controllers noted that they did not need the fixes very much since they could use the graphical trial planning tools in MACS.

\section{Observer Comments}

The observers suggested that whether a sector is familiar or unfamiliar is not so much the issue as is how much information the controller needs to learn and memorize to work traffic in a particular sector. In unfamiliar sectors, controllers tended to focus mostly on applying basic separation, whereas in familiar sectors they applied additional control techniques. The second set of five runs seemed easier for the controllers, since they had time to practice during the first five runs.

\section{Discussion}

The key results for evaluating the generic airspace concept include the three workload measures (WAK, postrun, and observer) and other data that address safety and the ability of the controllers to work in unfamiliar airspace. These findings support the hypothesis that controllers are able to manage unfamiliar airspace with an acceptable level of workload, perceptions of control, and safety, within the simulation environment employed in this study. These measures were not much different between unfamiliar and familiar sectors.

Data from the post-experiment questionnaire showed that the participants' level of familiarity with the sectors markedly improved by the end of the experiment. Ratings for the unfamiliar sectors after the study were less than one point (on the five point scale) lower that for the familiar sectors. Thus practice significantly improved familiarity, but not quite to the level of being equal to sectors the controllers had worked extensively during their careers.

In the post-experiment discussion, controllers said that they found working the unfamiliar sectors easier during the second set of runs. They indicated that there were some differences in how they managed traffic depending upon their level of familiarity with the sectors. While they thought the operations were manageable and safe, they indicated that more familiarity would have changed how they handled traffic. Without a deeper level of experience, they might be less knowledgeable about areas where conflicts might occur and not be able to pay as much attention to responding to pilot requests. The observers noted that in unfamiliar sectors, the controllers appeared to focus on basic control techniques, whereas they applied additional strategies in familiar sectors. Interestingly, several of the controllers said that there could be benefits from moving between a larger set of sectors. It could provide more variety to the job and might even increase alertness.

Although there were some losses of separation during the experiment, this did not definitely indicate that unfamiliar airspace was an issue. However, it is not clear why there were operational errors in this study, given that the workload was only moderate. (We were not able to make recordings of the radar screens due to technical constraints in the simulator.) The conflict rates, given the number of runs, were similar in both familiar and unfamiliar sectors. We had the conflict resolution parameters set for five miles or 1000 feet (the minimum separation standards). This did not leave much room for error if controllers were using the CD\&R tools in various situations.

There was little difference on MACS performance measures between familiar and unfamiliar sectors, including time aircraft spent in the sector, distance flown in sector, and number of data link uplinks. If there were differences in how the controllers managed traffic in familiar versus unfamiliar sectors, it was not detected by these metrics. 
The CIT was consulted mainly for adjacent sector numbers that were needed to initiate handoffs, and for route information. Controllers accessed the sector number information more often in the unfamiliar sectors. They responded that there was sufficient information to control traffic, and that it was readily available. Participants commented that the CIT worked well, but some preferred to have the display located lower down, so they do not have to look up to read the data. They had a few suggestions for additional content to be added to the CIT.

The NextGen tools we used for this study included data link for all clearances. There was also CD\&R set for a ten-minute look ahead, and conflict resolutions on demand. The controllers generally liked the data link environment, and gave it high ratings in the final questionnaire. There was some indication that the user interface could be more efficient. The conflict probe was also deemed useful, though we noted several false alarms due to simulation software problems during the scenarios, sometimes in overtaking situations. The conflict resolutions obtained lower controller ratings. Participants commented that a setting of more than the five-mile limit we used would probably make the conflict resolutions seem more trustworthy. Resolutions sometimes did not make sense (e.g., turning one aircraft in front of the other). Controllers did not always use the conflict resolution tool.

\section{Conclusions}

The purpose of this experiment was to test whether a generic airspace concept that includes providing controllers with important sector data and NextGen automation tools would help them manage unfamiliar airspace. In any future system that employs generic airspace, controllers would be trained and experienced on all of the sectors they would control, even if the number was higher than today. Placing our participants in front of unfamiliar sectors to which they only had a brief introduction was "unfair" in a sense, since they were not provided with any formal training or practice. The results we obtained, then, may be for a more difficult case than would be found in a future air traffic control environment, such as a high altitude facility.

All of the indicators from this study that addressed workload, traffic management, and safety, as well as controller and observer comments, supported the concept. The unfamiliar sectors were comparable to the familiar sectors for all relevant measures.

The airspace information presented for the controllers was an important component of the generic airspace concept. Data link seemed to reduce the need for controllers to access sector frequency information, and perhaps also NAVAIDS. It is probably safe to assume that data link facilitates the generic sector concept by reducing the amount of information that has to be memorized by the controller, though this needs to be confirmed by further research.

It is not certain from this study whether CD\&R is an essential enabler for the generic airspace concept. We suggest that the ten-minute conflict detection probe, which received positive ratings, is a good feature to include. It provides the controller, who may not have worked a generic sector for a while, with some backup or a "safety net" to provide alerts about conflicts in the areas of the sector where conflicts might occur. More work needs to be done to understand conflict resolution tools before we can be certain that they are needed to support generic airspace.

The maximum traffic counts in our scenarios were below the MAP values for the actual sectors and this may have accounted for the moderate workload ratings. Sector complexity ratings made by observers were also in the moderate range. While the generic airspace concept seems to work well under these conditions, it is not known at this point how controllers would respond to higher traffic levels or unusual situations. This is where the NextGen tools might be more important to help reduce workload and control errors.

Should the generic sector concept move forward, it is clear from this study that even a limited amount of prior exposure to an unfamiliar sector can have benefits. Our participants commented on this, and indicated that their familiarity increased substantially after only two sessions on unfamiliar sectors. Should controllers eventually manage a larger set of sectors than today, an opportunity to practice for a short period of time prior to starting work in a fresh area would be helpful. This could be done in a training room, where controllers who are about to work a sector they have not seen for a while, could view a pre-recorded briefing or orientation, and work a sample traffic problem. For generic airspace, there may be a benefit to assigning more highly skilled or adaptable controllers to the environment, in that they may be more successful. 


\section{Recommendations:}

1. Conduct further generic airspace research to investigate the robustness of the concept under higher traffic levels and in conditions where there are off nominal events, such as weather, emergencies, or automation failures.

2. Add further conditions to the automation environment, including TBO and sector management (e.g., combining/decombining ${ }^{11}$ ), which are part of the FAA's Mid-term, High Altitude Airspace Concept.

3. Consider moving the data that are currently displayed on the CIT to the main radar display.

4. Conduct further development on the data link user interface to improve efficiency and usability.

5. Conduct further work on the CD\&R tools to improve accuracy, reliability, and acceptance.

\section{Acknowledgments}

The author sincerely thanks the Generic Airspace Team including Mark Evans, Rod David, Jim Gibson, Vimmy Gujral, Jim Miller, Dan Peknik, Jacob Pfeiffer, Bill Preston, John Shih, Kendrick Wang, and Forrest West. Generic airspace research is part of NASA's Dynamic Airspace Configuration Research Focus Area at the NASA Ames Research Center. It is funded by the NASA NextGen Concept and Technology Project and by the FAA ATO Planning, Research, and Technology Office. The author wishes to thank Parimal Koparkekar (NASA Ames), Shannon Zelinski (NASA Ames), and Anton Koros (William J. Hughes Technical Center) for their support.

\section{References}

${ }^{1}$ Joint Planning and Development Office, "Next Generation Air Transportation System Integrated Plan,” [online publication] URL: http://www.jpdo.gov/library/NGATS v1 1204r.pdf [cited 24 August 2010].

${ }^{2}$ Kopardekar, P., Bilimoria, K., and Sridhar, B., "Airspace Configuration Concepts for the Next Generation Air Transportation System," Air Traffic Control Quarterly, Volume 16, Number 4, 2008.

${ }^{3}$ Brinton, C., and Pledgie, S. "Airspace Partitioning Using Flight Clustering and Computational Geometry," 27th Digital Avionics System Conference, St. Paul, Minnesota, 2008.

${ }^{4}$ Xue, M., "Airspace Sector Redesign Based on Voronoi Diagrams," AIAA Guidance, Navigation and Control Conference and Exhibit, Honolulu, Hawaii, 2008.

${ }^{5}$ Yousefi, A., Khorrami, B., Hoffman, R., and Hackney, B., "Enhanced Dynamic Airspace Configuration Algorithms and Concepts," Metron Aviation Inc., Tech. Rep. Report No. 34N1207-001-R0, December 2007.

${ }^{6}$ Kalbaugh, S. K., and Levin, P., "Universal High Altitude Airspace (UHAA) Mid-term Concept,” MITRE Corp., Ltr. F063L07-075, September 2007.

${ }^{7}$ Levin, K. M., "Universal High Altitude Airspace (UHAA)," Presentation, February 2007.

${ }^{8}$ Federal Aviation Administration, “An Operational Concept for Mid-Term High Altitude (High Performance-Based) Airspace,” Version 4.17 (draft), William J. Hughes Technical Center, January 2010.

${ }^{9}$ Federal Aviation Administration, Order JO 7210.3W, "Section 7. Monitor Alert Parameter," [online publication] URL: http://www.faa.gov/documentLibrary/media/Order/FAC.pdf [cited 24 August 2010].

${ }^{10}$ Stein, E. S., "Air Traffic Controller Workload: An Examination of Workload Probe.” (DOT/FAA/CT-TN84/24). Atlantic City International Airport, NJ: Federal Aviation Administration Technical Center, 1985.

${ }^{11}$ Bloem, M, and Gupta, P., "Configuring Airspace Sectors with Approximate Dynamic Programming," Proceedings of the $27^{\text {th }}$ Annual Congress of the Aeronautical Sciences, Nice, France, 2010. 


\title{
Generic Airspace Concepts and Research
}

\author{
Richard Mogford, Ph.D. \\ and \\ The Generic Airspace Team
}

September 14, 2010 


\section{Overview}

- Background

- Phases 1 and 2 Research

- Phase 3 Research

- Summary 


\section{Background}

- In the current en route system, controllers are checked out on only five to seven sectors

- Significant time is required to learn airspace and procedures

- The Next Generation Air Transportation System (NextGen) will introduce changes in airspace usage and design

- Controllers may move between more sectors to work traffic, as determined by system needs

- Dynamic re-sectorization may redefine airspace boundaries based on traffic flow, weather, etc.

- New operational concepts will require different airspace structure and procedures

- The current paradigm may limit NextGen concepts

- How can we make airspace easier to learn and manage? 


\section{Management of Airspace}

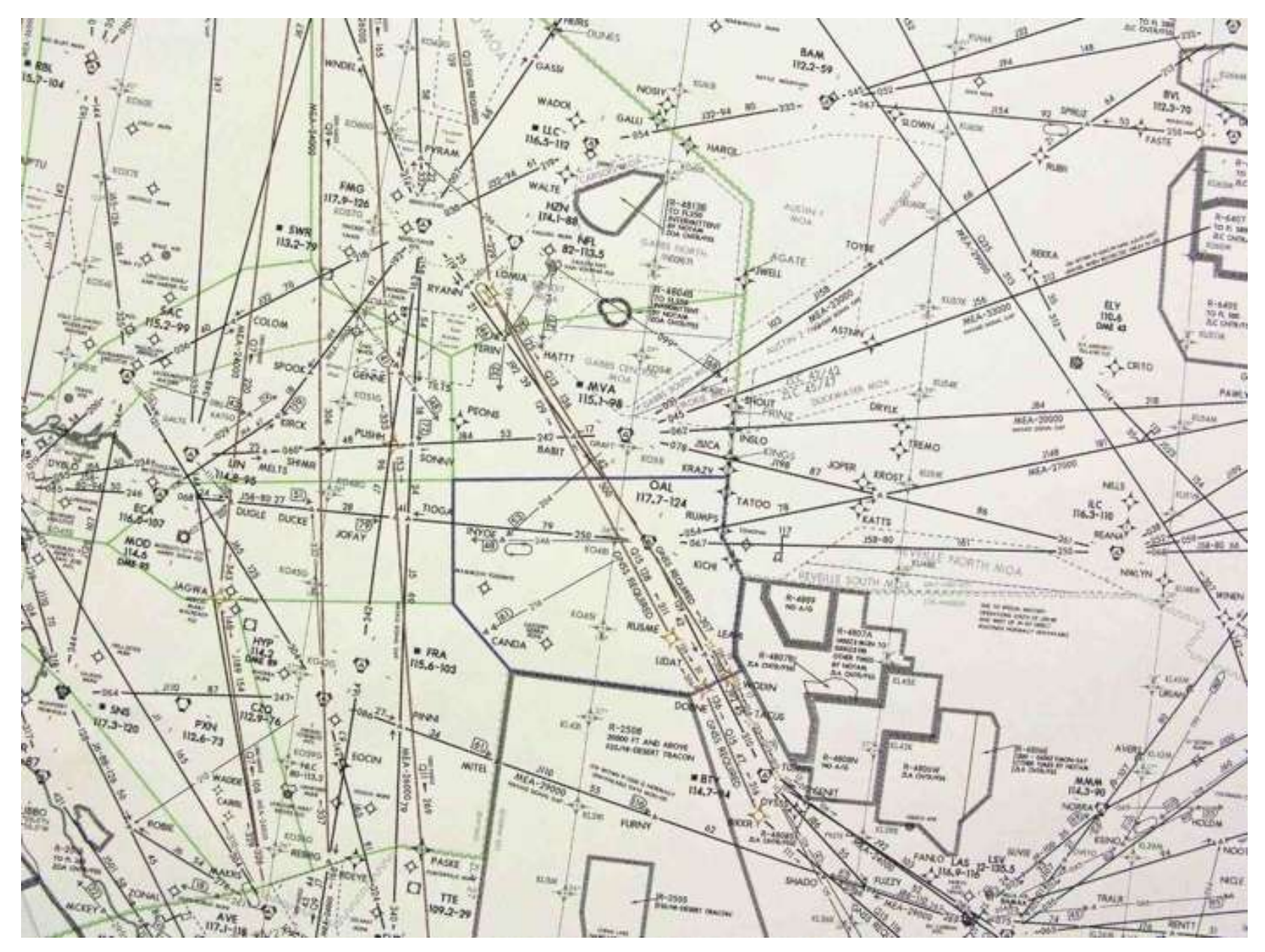

Skills plus information 


\section{Generic Airspace Strategies}

Three approaches for making airspace easier to learn and manage:

1. Identify sector information needed by the controller and display it at the radar position

2. Incorporate automation

- Can eliminate or reduce the need for memorizing sector information

3. Modify sector characteristics or topography

- Change boundaries, shape, size, navigational references, labeling, etc.

Prior research: Universal High Altitude Airspace study conducted by MITRE. 


\section{Approach}

- Created a "Controller Information Tool" (CIT) to assist controllers to manage unfamiliar sectors

- Met with Airspace and Procedures Office at Oakland Center (ZOA) to determine information needed by controllers

- Sector boundaries

- Special Use Airspace

- Altitudes, frequencies, and sector numbers

- Fixes and navigational aids

- Typical traffic flows

- Procedures and Letters of Agreement

- Chose Sector 33 in ZOA (high altitude) for initial generic airspace research

- Started development and testing 


\section{Controller Information Tool}

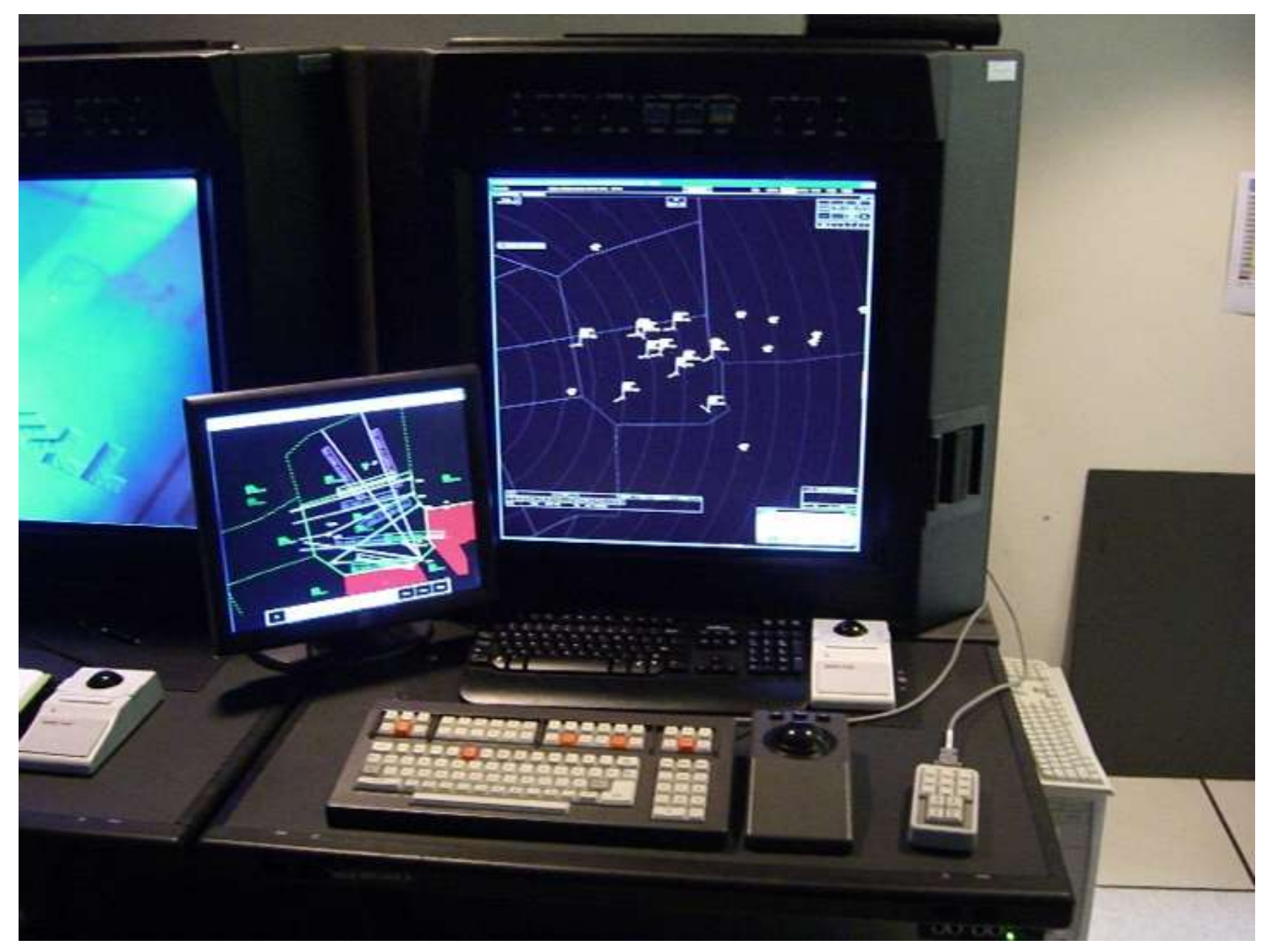




\section{Sector Data}

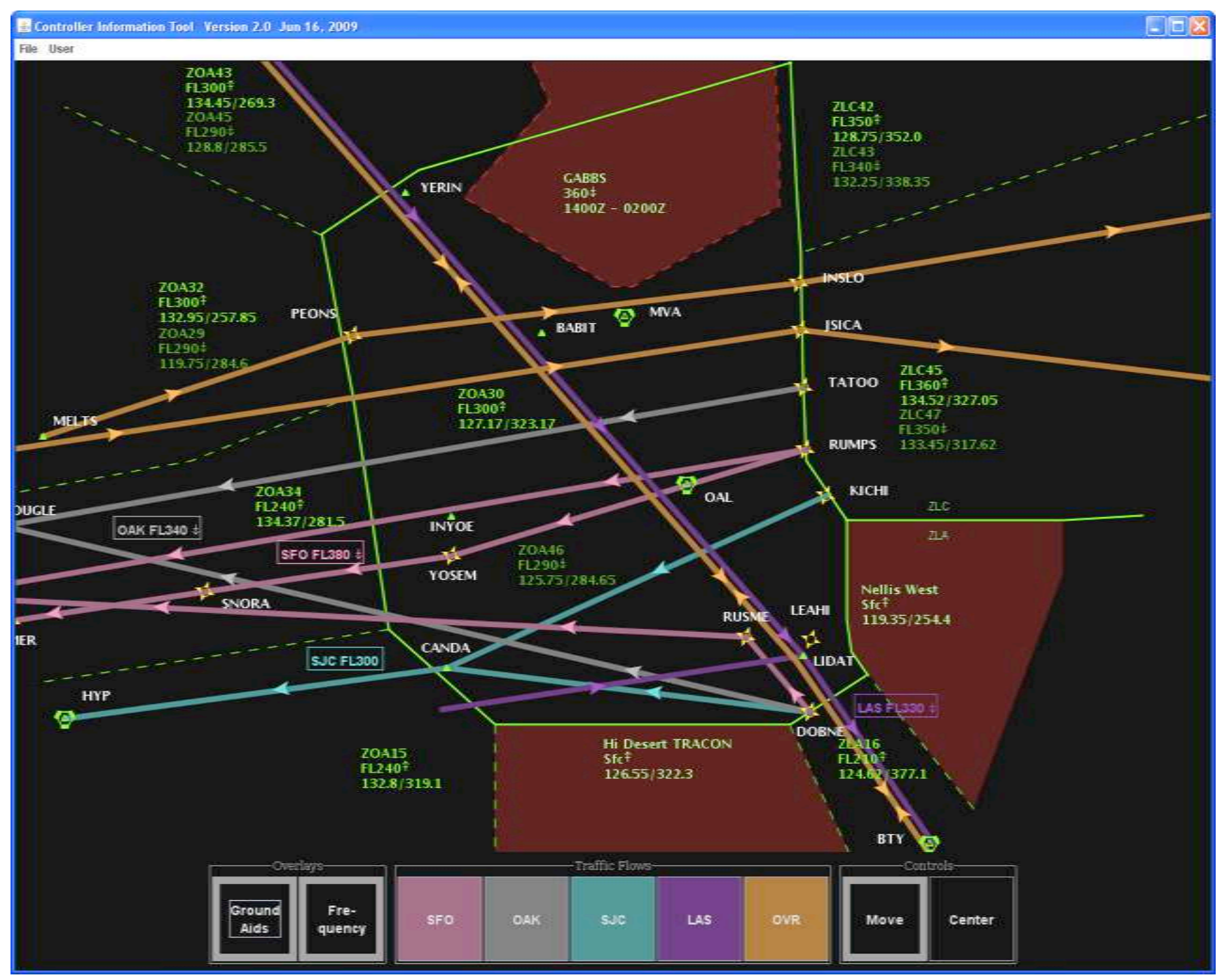




\section{Effects of NextGen Concepts: Data Link}

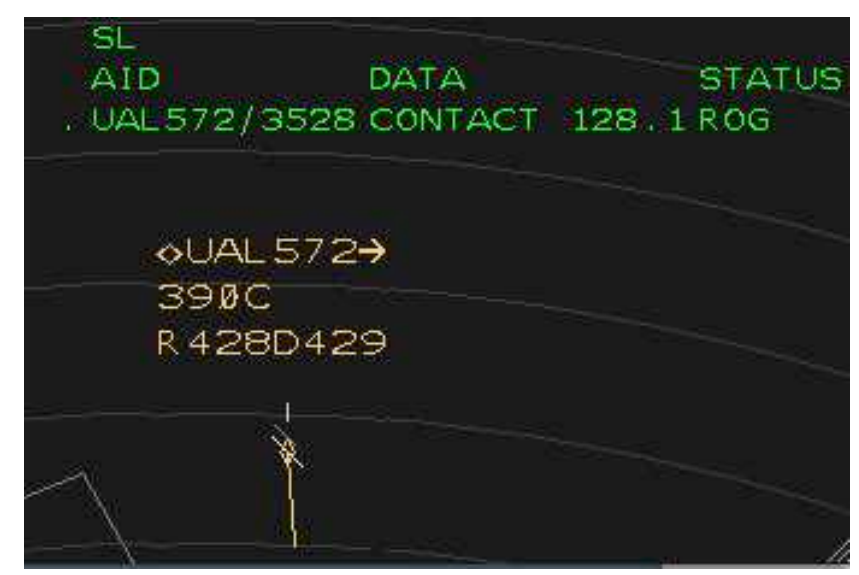

Controller Data Link User Interface

Data link is used to transfer aircraft to next sector frequency. 


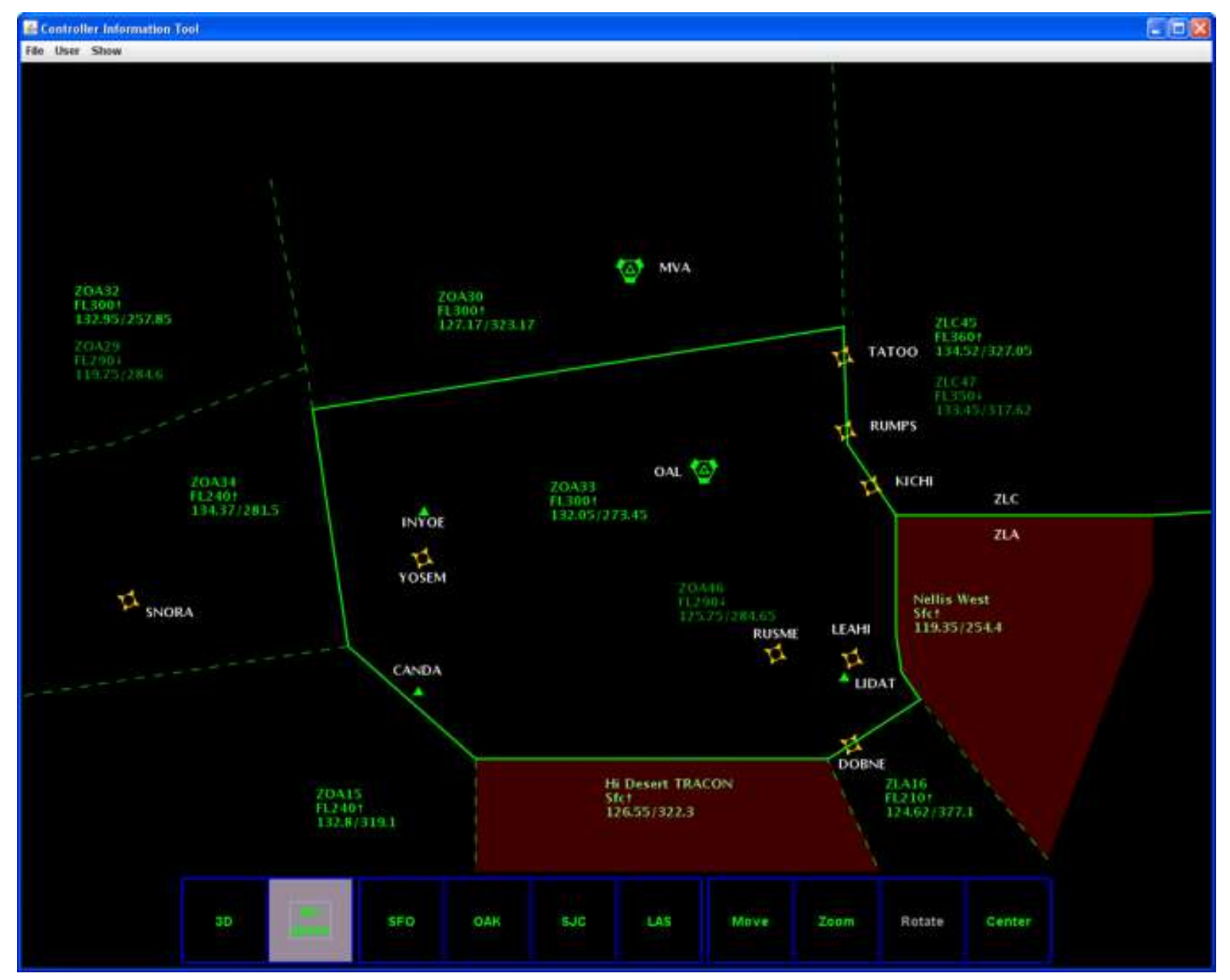




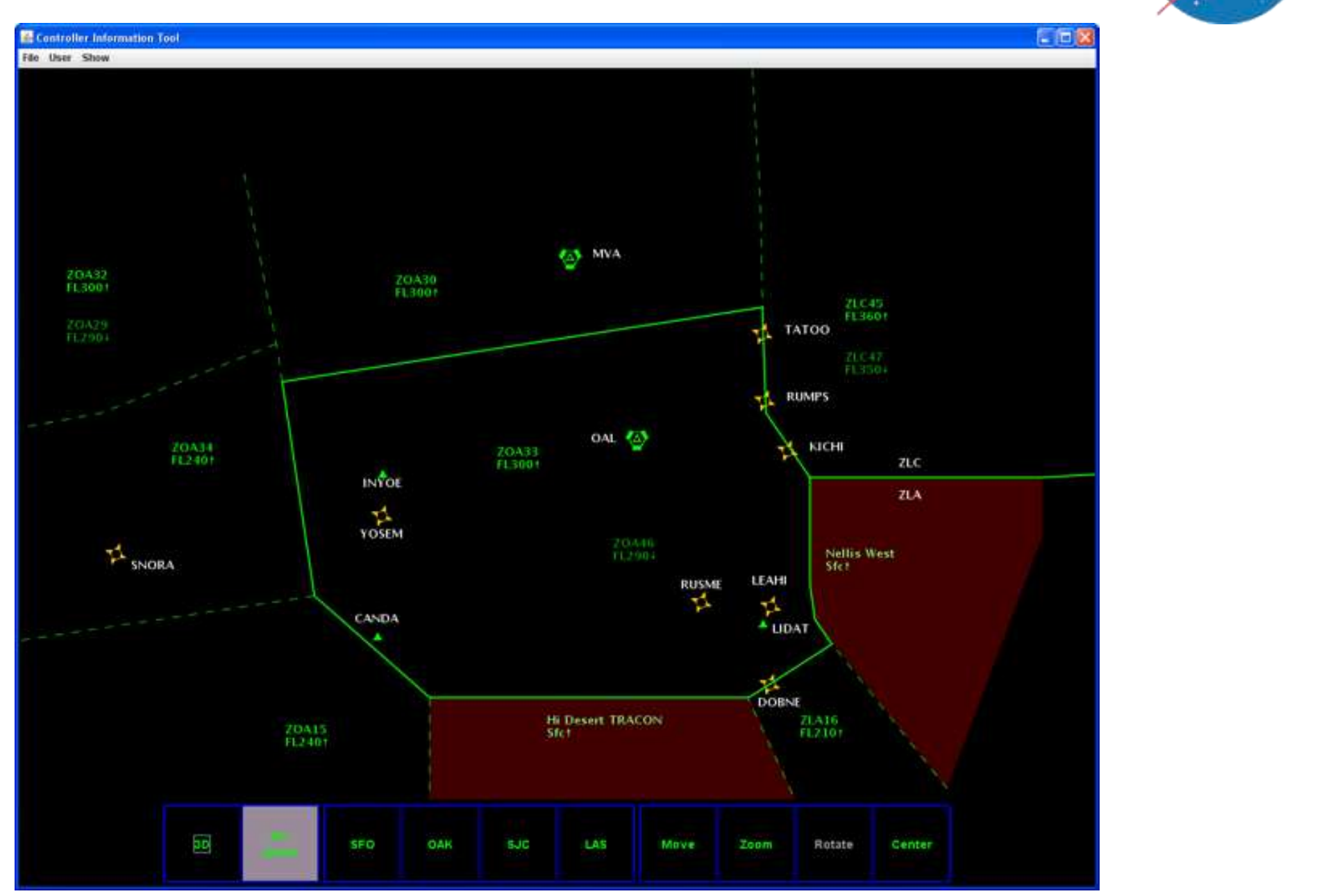

Controller no longer needs to remember adjacent sector frequencies. 


\section{Effects of NextGen Concepts: Graphical Route Changes}
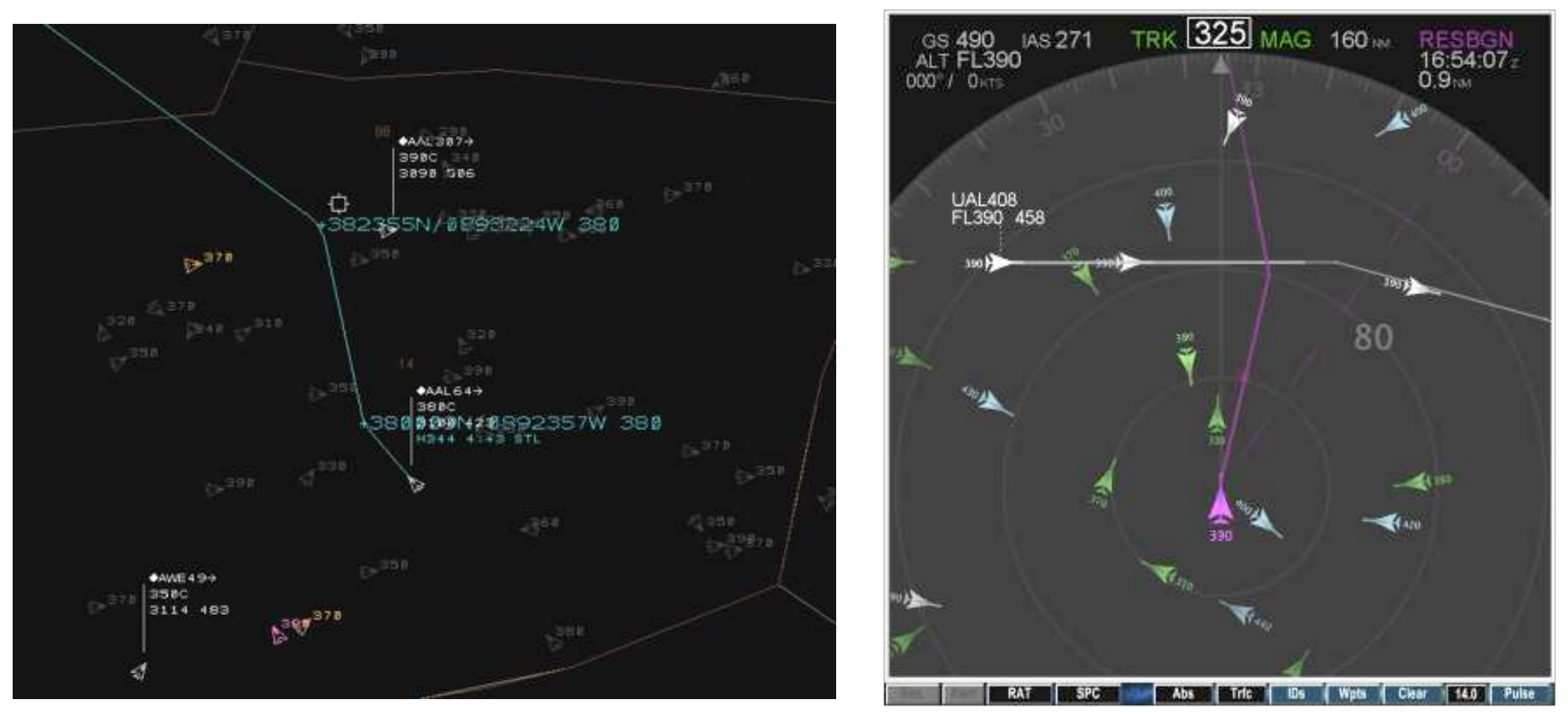

ATC

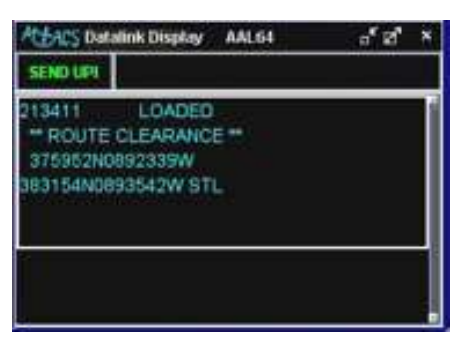

Flight Deck

Graphics-based tools are used to communicate, visualize, and modify flight paths, using data link. 


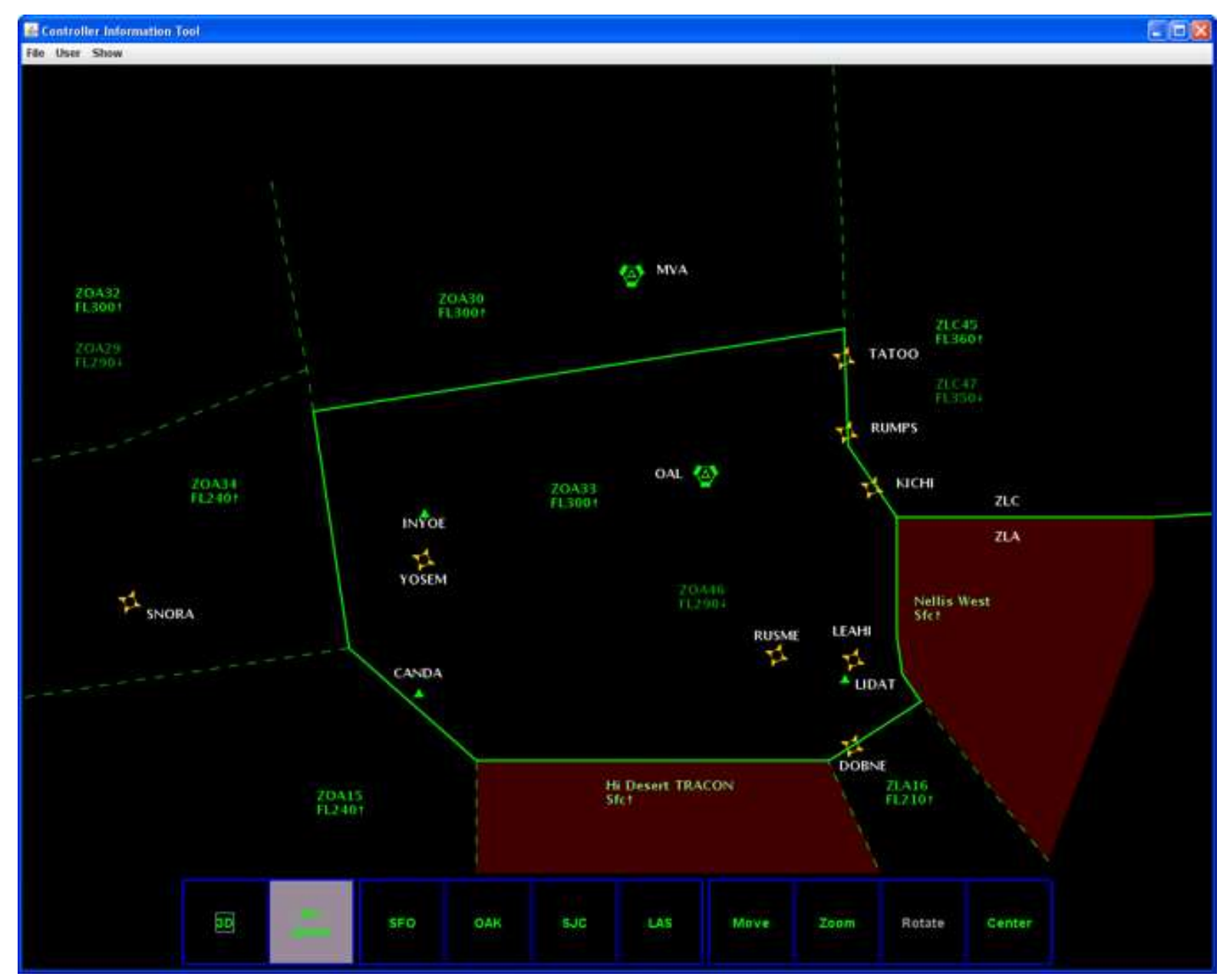




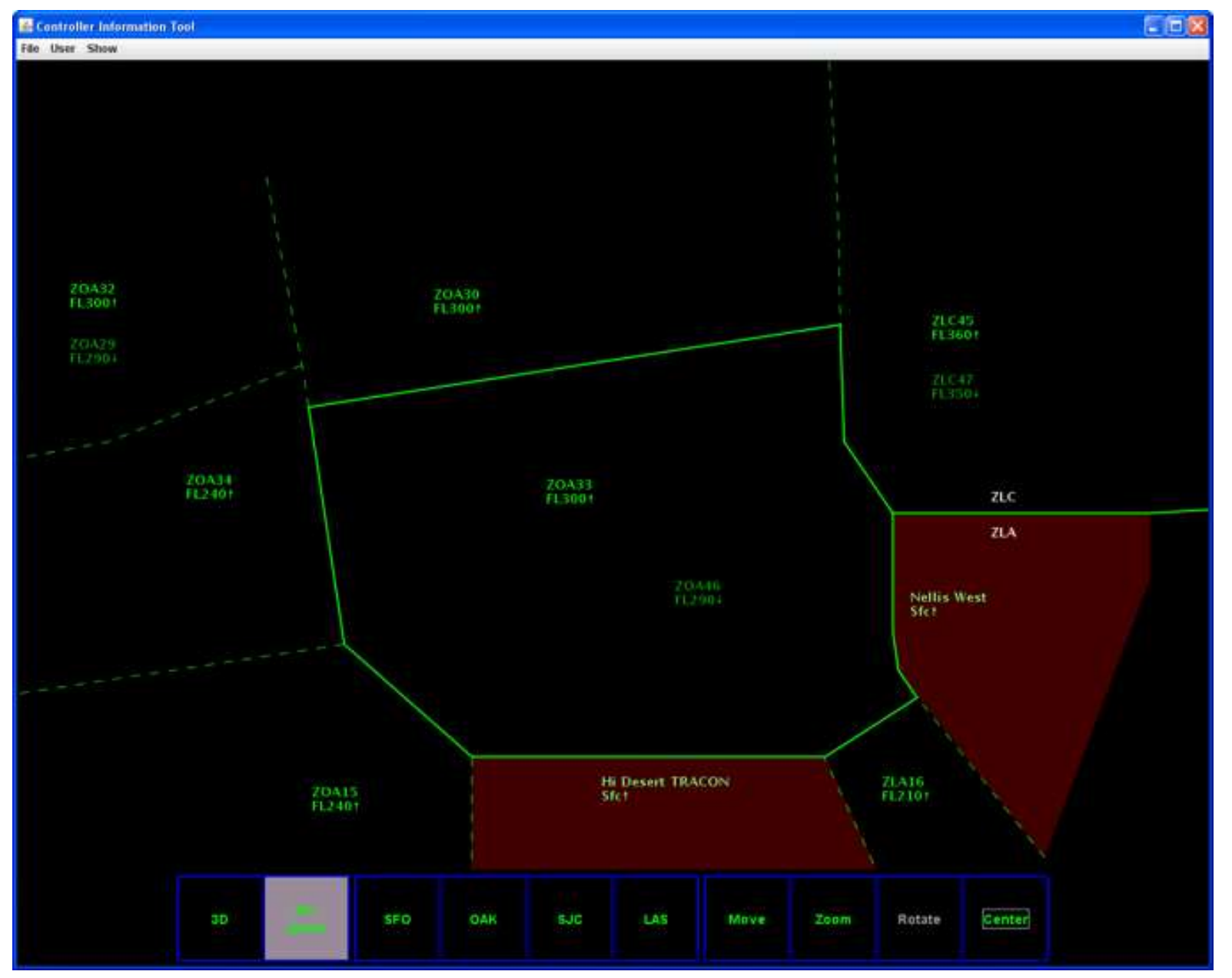

Navigational references no longer need to be memorized. 


\section{NextGen Concepts Support Generic Airspace}

- Outcomes

- Lower workload, improved safety

- Controllers have less requirement to use sector frequencies and navigational references

- NextGen automation reduces the amount of data that the controller needs to learn, recall, and actively retain in memory

- Also results in more predictable flight trajectories (Trajectory Based Operations [TBO] or 4D trajectories) 


\section{Phases 1 and 2 Results}

- Basic testing completed

- Generic sectors initially seemed to be feasible

- Required sector information can be provided on a work aid or on an existing display

- NextGen automation tools simplify information needs

- Generic sectors may be practical in higher-complexity airspace than originally expected (e.g., ZOA 33)

- Further research

- Start formal testing

- Support FAA's Mid-term, High Altitude, Trajectory-based Airspace Concept 


\section{FAA High Altitude Concept}

FL 600

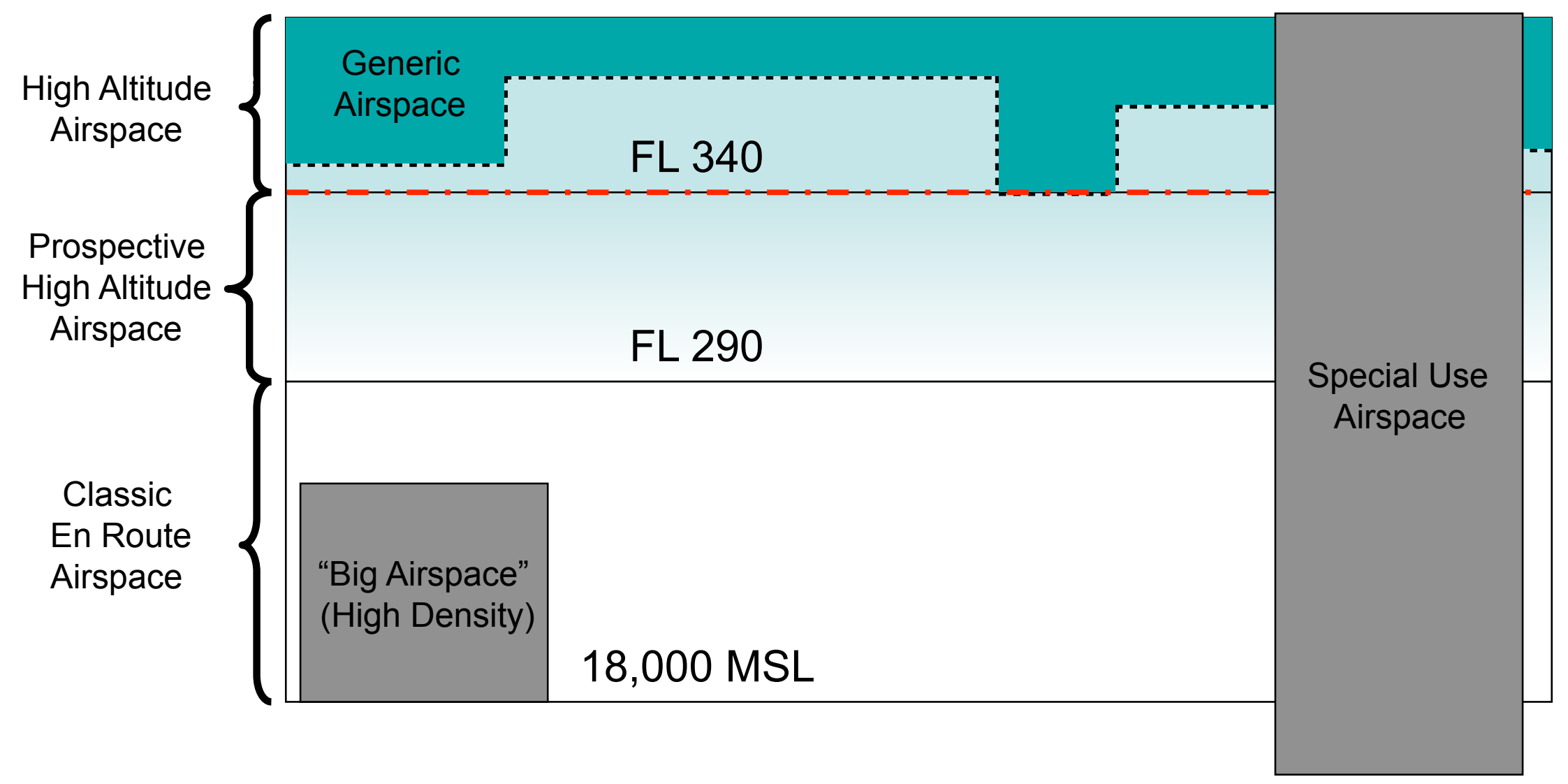

- The base of high altitude airspace may vary across the NAS

- All generic sectors are contained within high altitude airspace

- TBO will be introduced first in high altitude airspace

- Access to high altitude airspace will be restricted to equipped aircraft 


\section{Phase 3 Experiment}

- Human-in-the-loop experiment

- Conducted week of December 14, 2009

- Research goals:

- Determine whether controllers can manage unfamiliar sectors with an acceptable level of efficiency and safety, as compared to familiar sectors

- Provide data to calibrate dynamic density metrics for generic sectors

- Test environment

- Created a "West High Center" which included ZOA sectors 30, 33 and 43, and Salt Lake (ZLC) sectors 42 and 45

- Data link for transfer of communication and for sending route changes and clearances

- Manual conflict detection and resolution (CD\&R) for managing separation

- Presented the information needed by the controllers to manage each of the five sectors 


\section{"West High Center" Airspace}

Map from MITRE UHAA Concept (9/07)

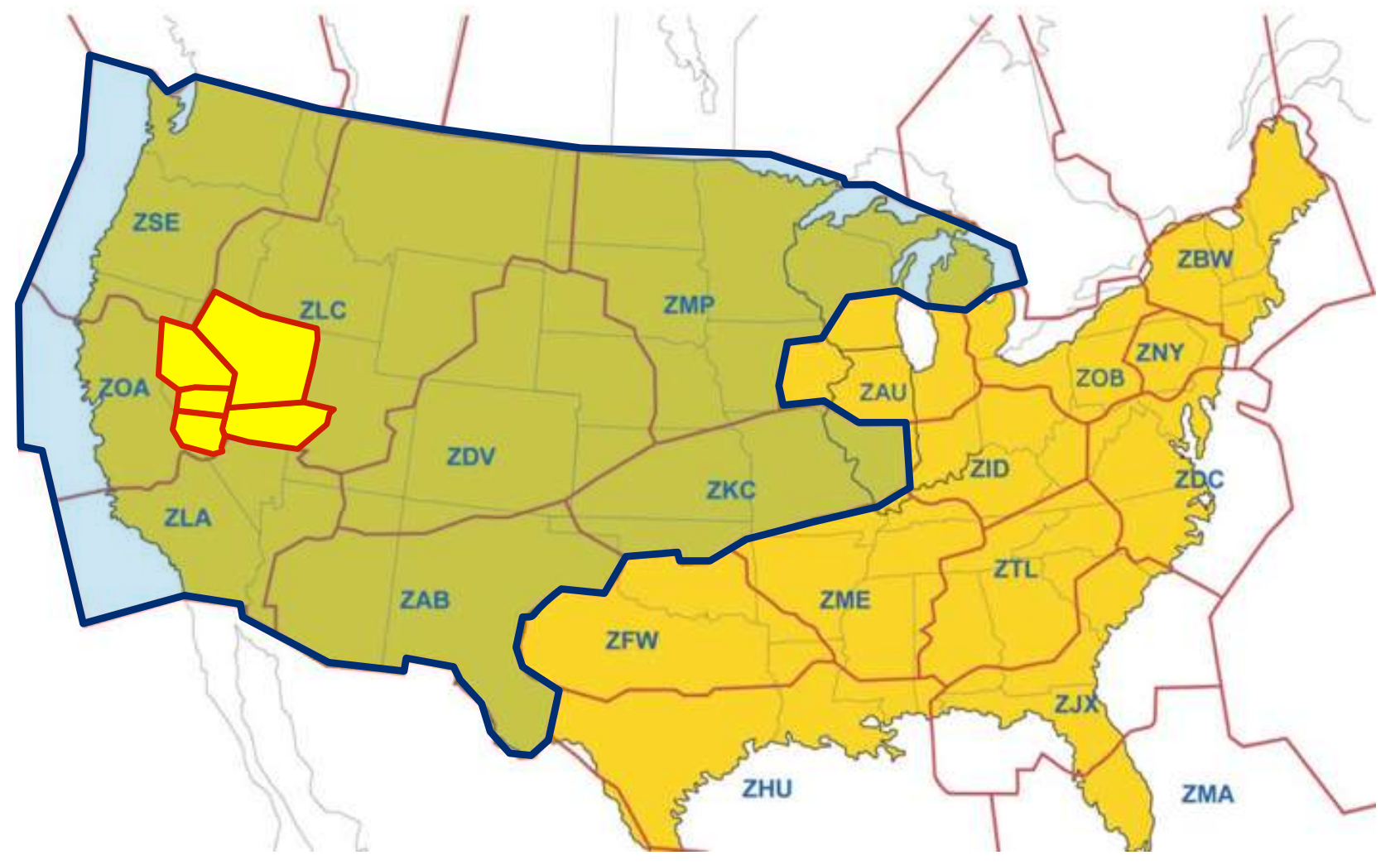

Five contiguous sectors were treated as a subset of a notional high altitude facility (West High Center - ZHW). 


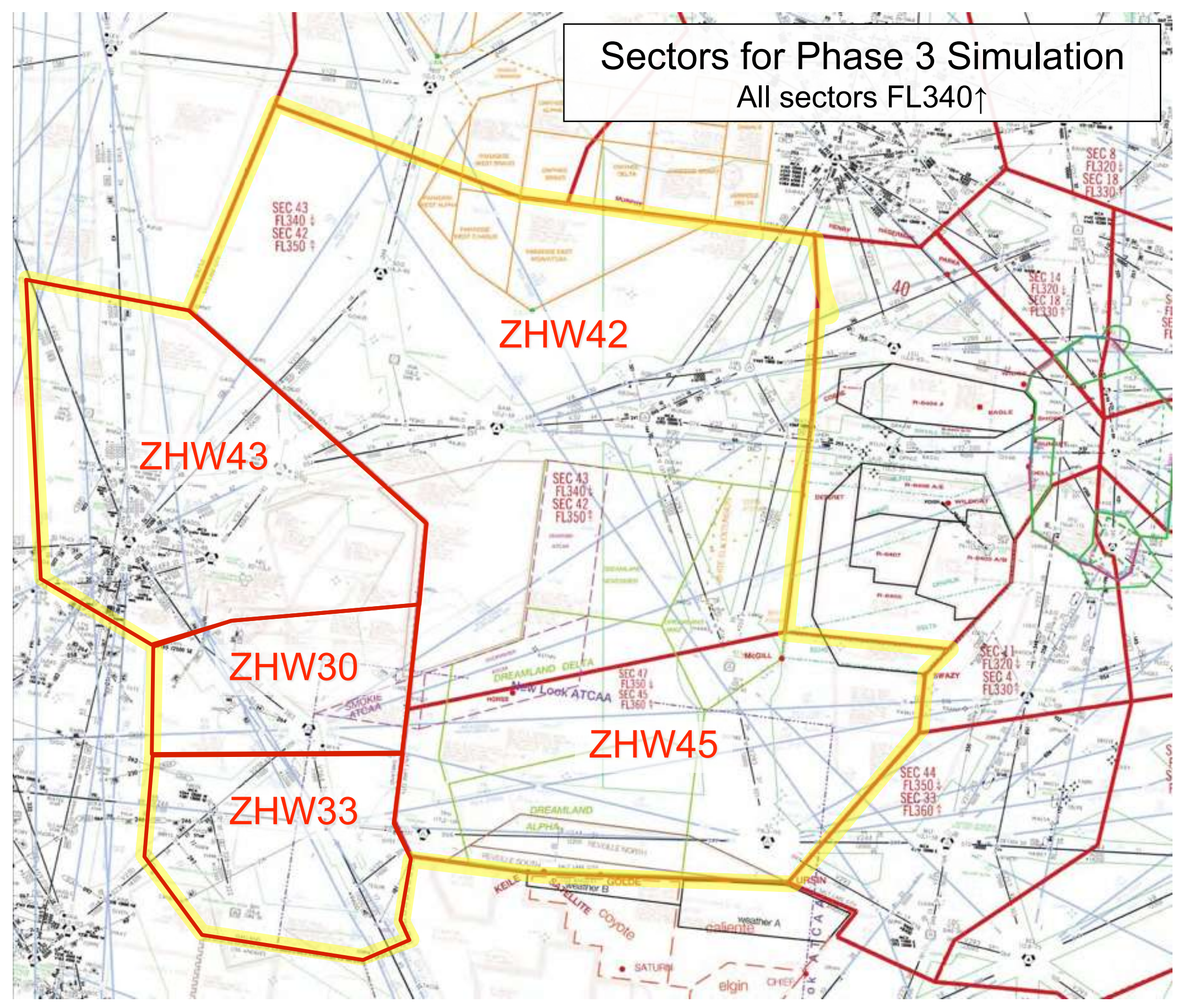




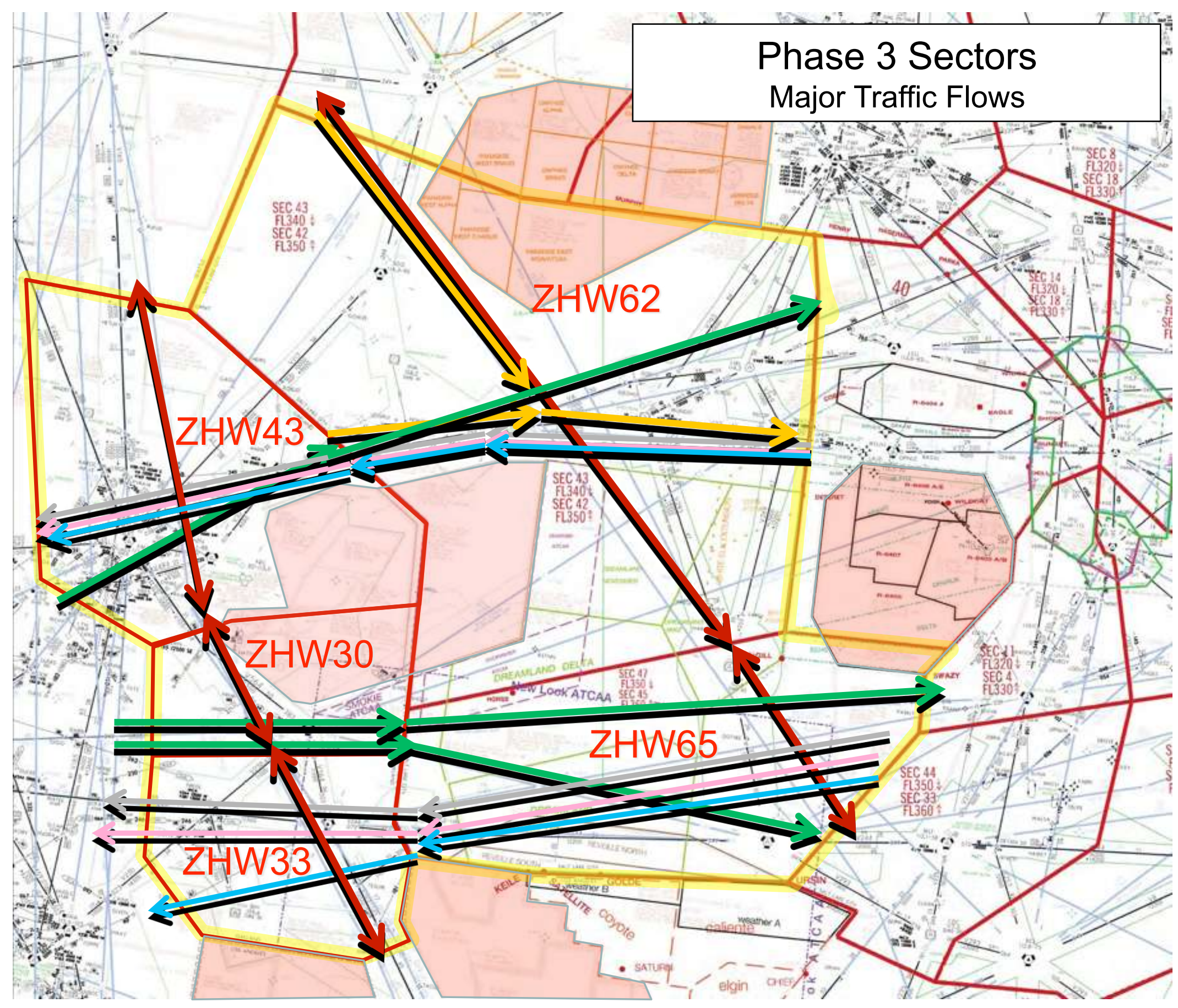




\section{Phase 3 Sector Data}

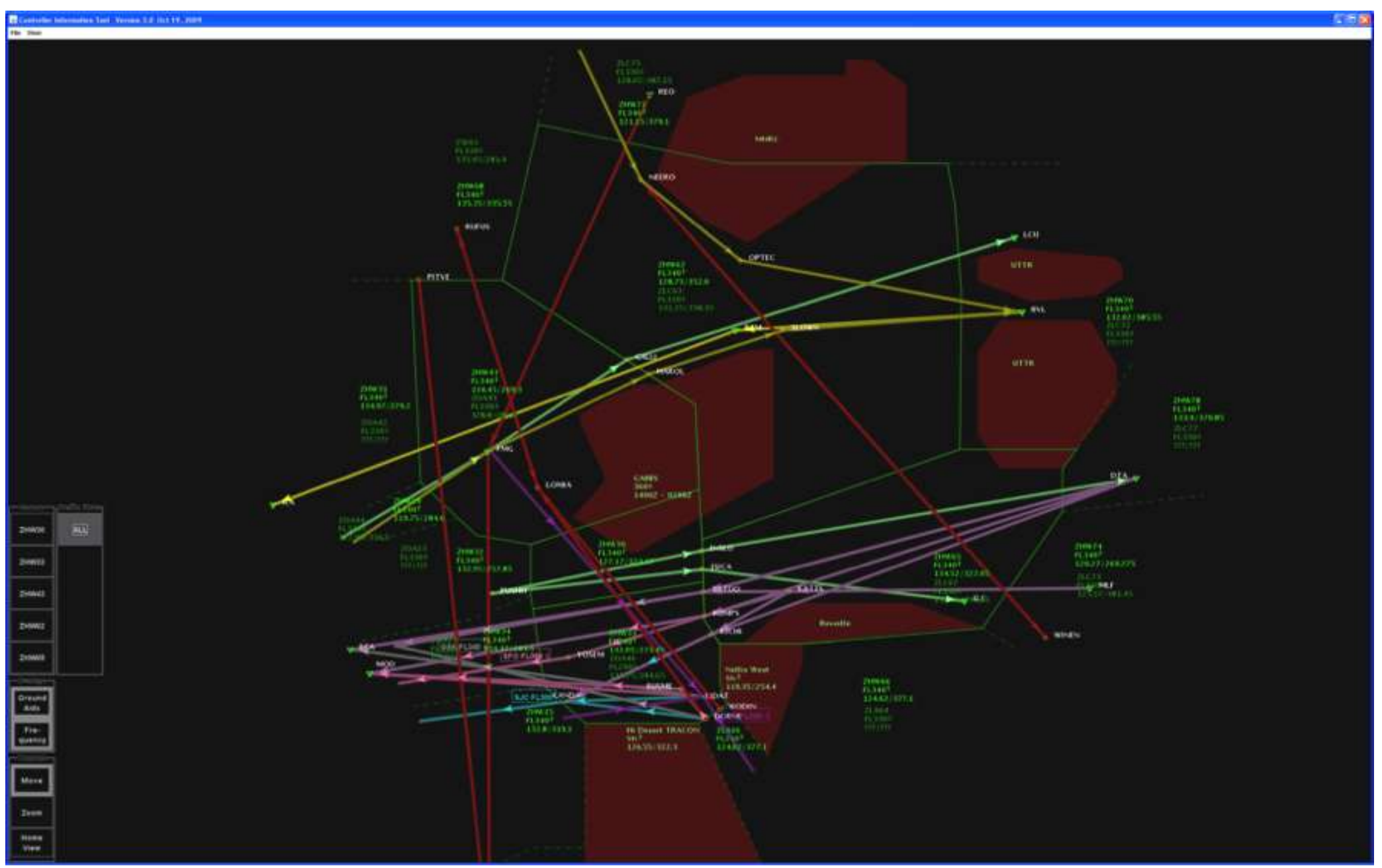




\section{Single Sector View}

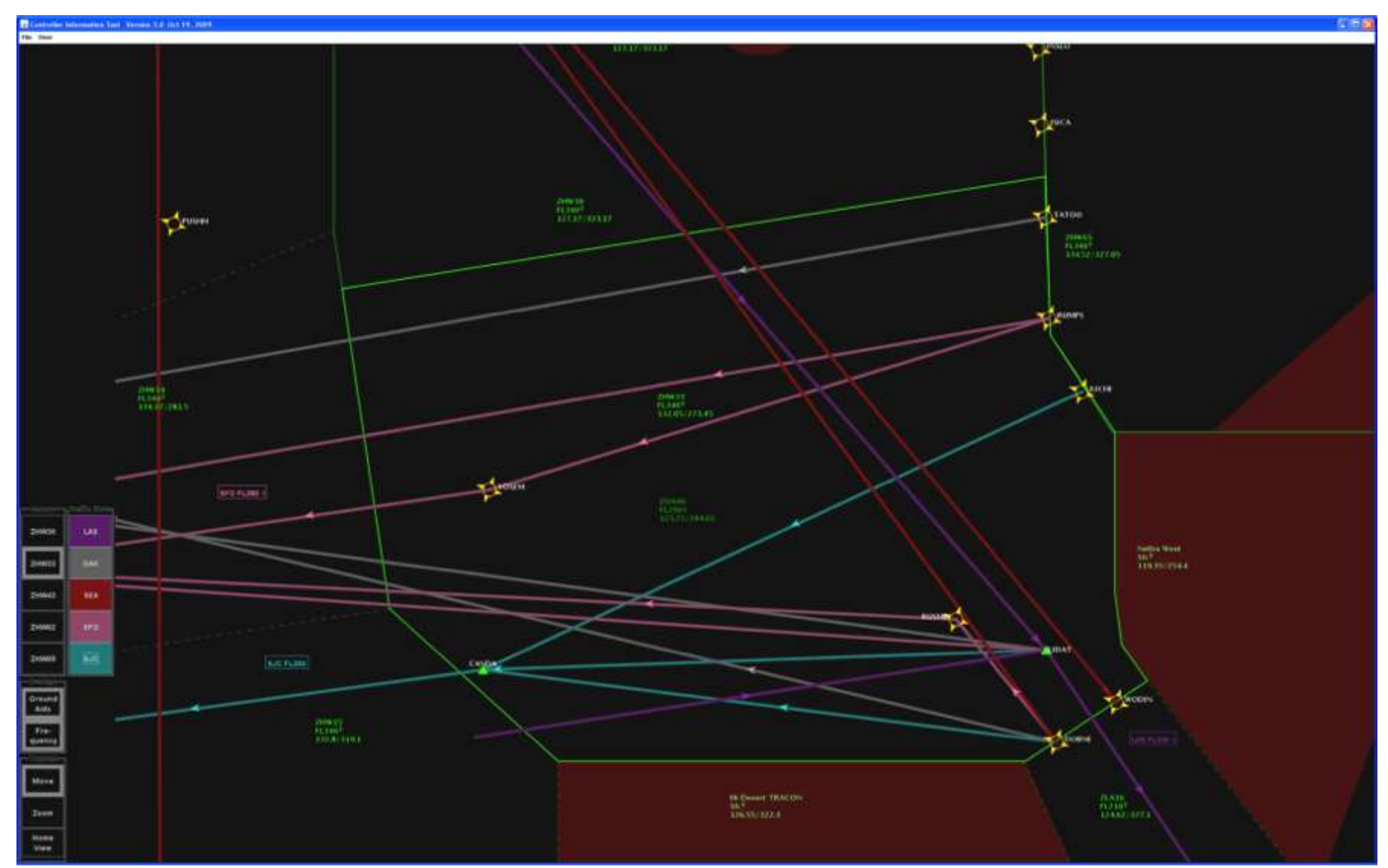




\section{Laboratory Layout}

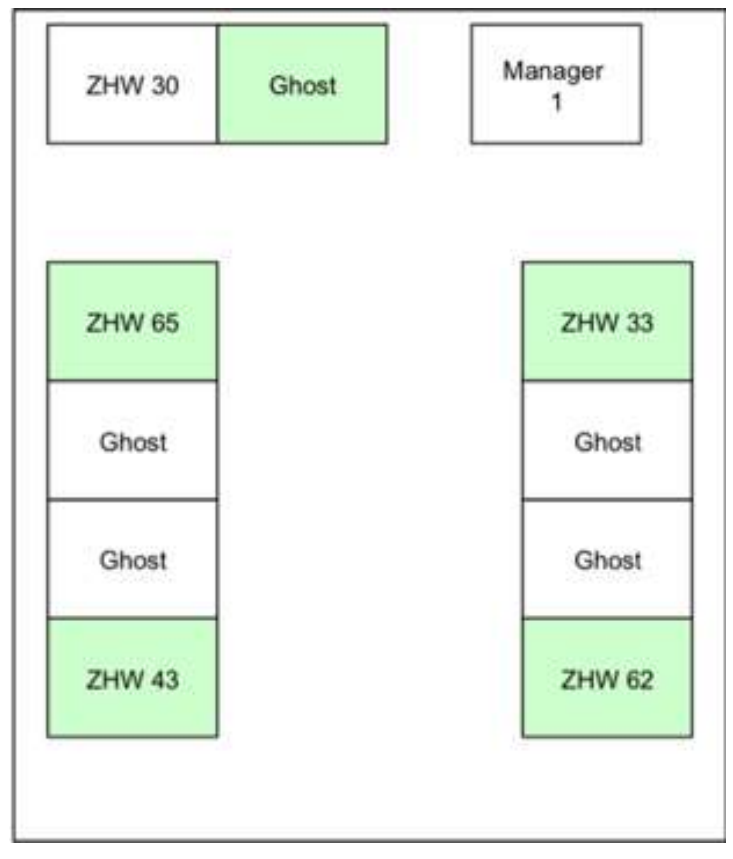

Laboratory Floor Plan

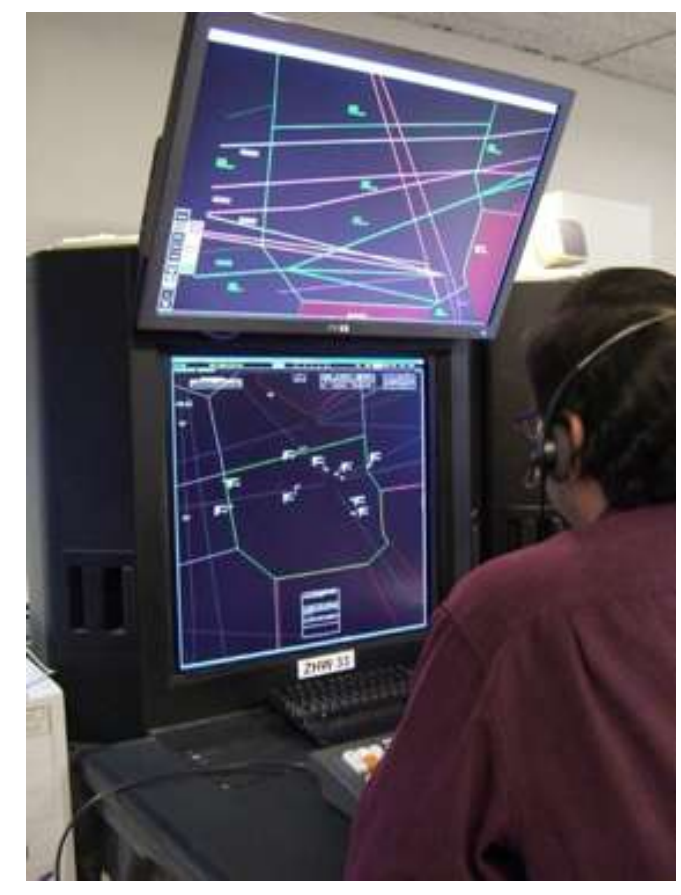

Sector Information 


\section{Method}

- Experimental design

- Five retired controllers, each familiar with one or two sectors, but not the others

- Each controller worked all five sectors twice

- Normal traffic conditions

- Counterbalanced runs to reduce practice effect

- Procedures

- Participants were first given an orientation to the study

- Then trained on automation tools with three runs on low to medium traffic

- Given an overview of operations in the West High Center

- Introduced to CIT

- Then ran 10 data collection trials 


\section{Method}

- Data collection

- On-screen Workload Assessment Keypad (WAK) input every five minutes

- Frequency of access to sector data

- Post-run questionnaire (workload and other measures).

- Multi Aircraft Control System metrics (operational errors, etc.)

- Post-experiment questionnaire

- Over-the-shoulder data collected by controller observers (including workload ratings)

- Post-experiment debriefing to collect additional information

- Data to calibrate dynamic density measures 


\section{Results}

- Generic airspace concept seemed to be feasible (within study conditions)

- Controllers found it acceptable to manage unfamiliar sectors, with the assistance of NextGen tools and important sector data

- Observers agreed with this finding

- Data supported these findings

- Workload measures collected every five minutes and after each run showed small workload differences between familiar and unfamiliar sectors

- Participants reported feeling in control of traffic and that safety was maintained

- Found the sector data presented to be very helpful

- There were nine losses of separation during the simulation, about equivalent between familiar and unfamiliar sectors ( 0.17 versus 0.18 conflicts per run) 


\section{Results}

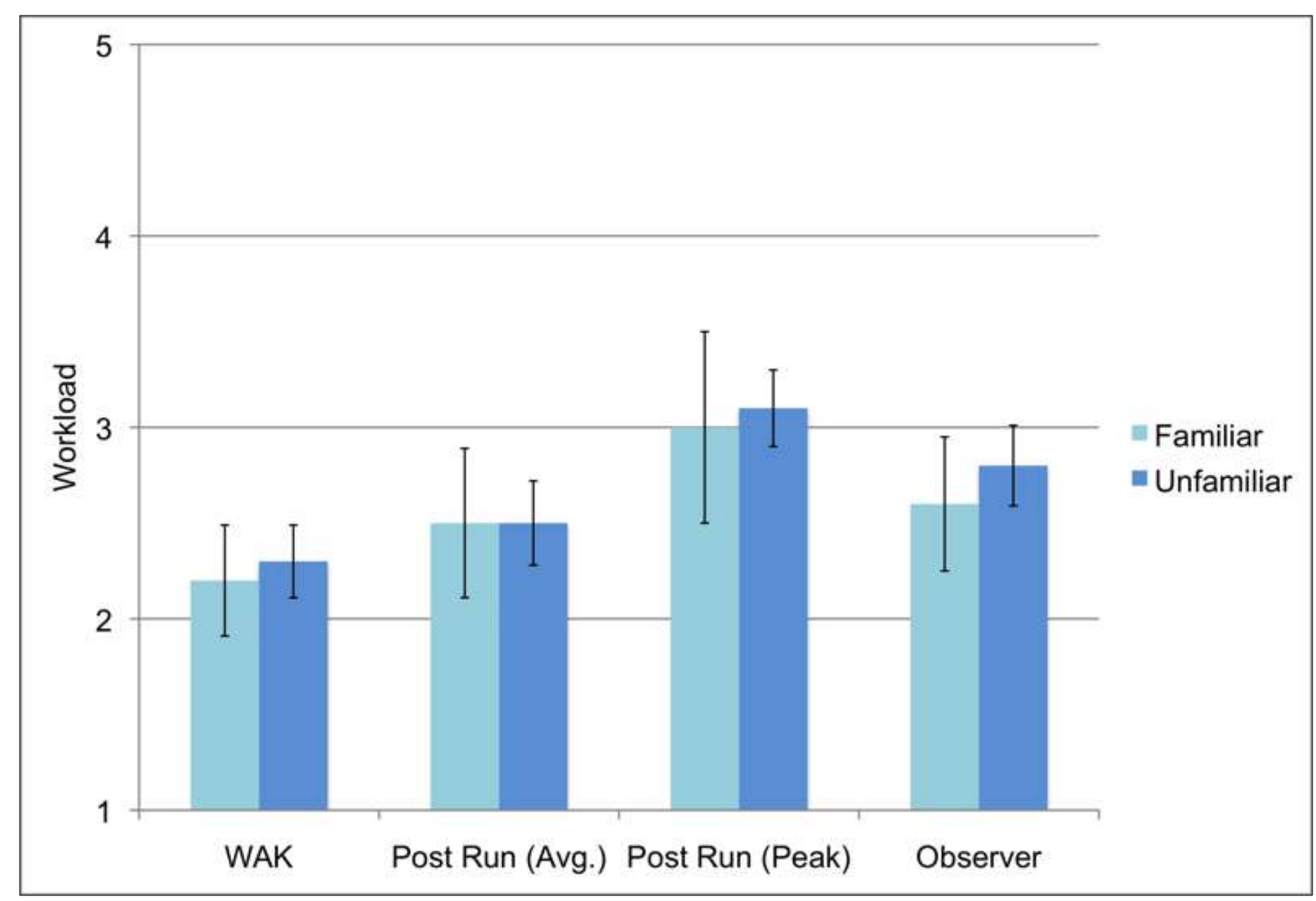

Comparable workload ratings for familiar and unfamiliar sectors. 


\section{Results}

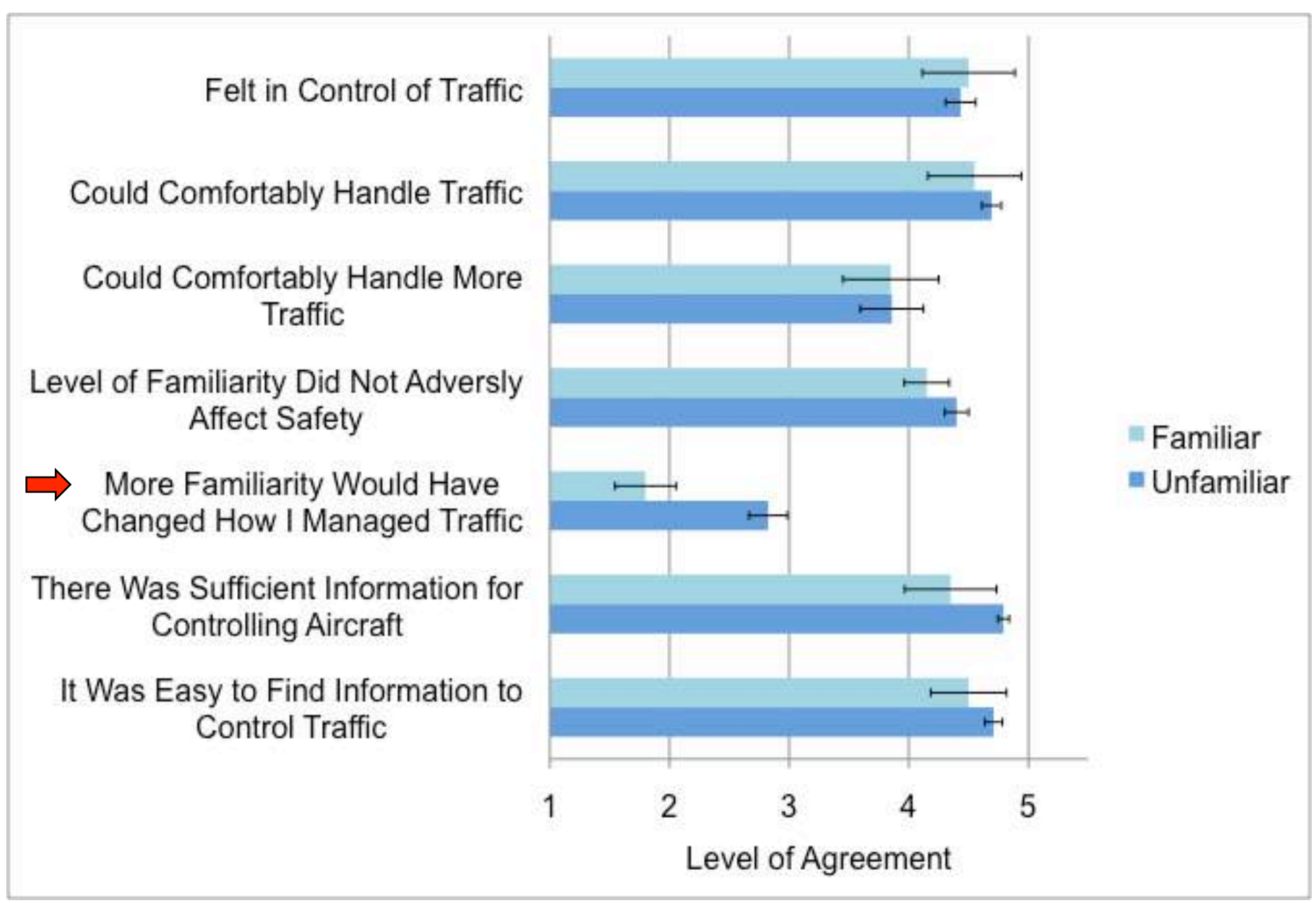

Acceptable ratings for both familiar and unfamiliar sectors.

$$
\Rightarrow \text { = statistically significant difference }
$$




\section{Results}

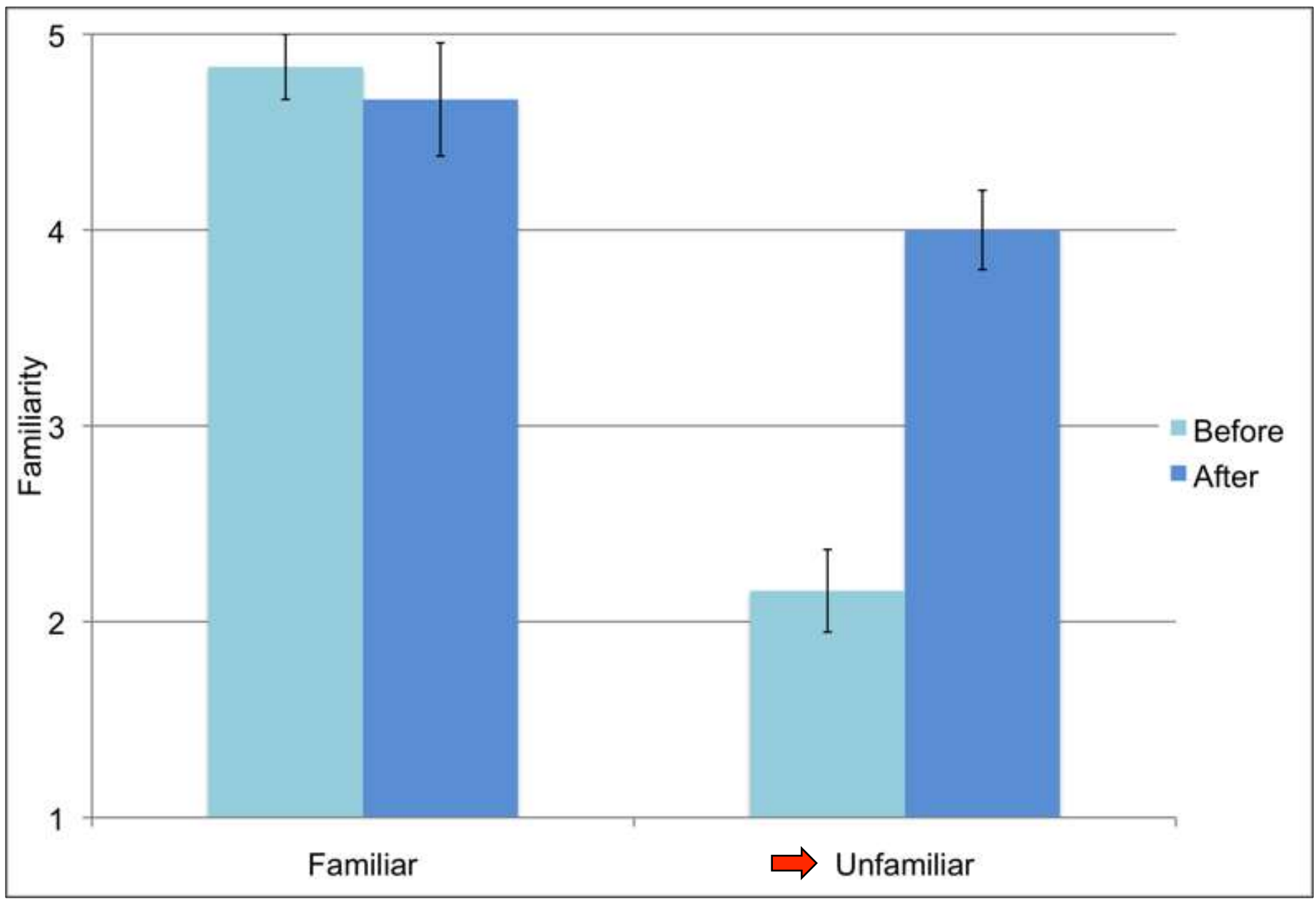

Familiarity with sectors before and after simulation. 


\section{Results}

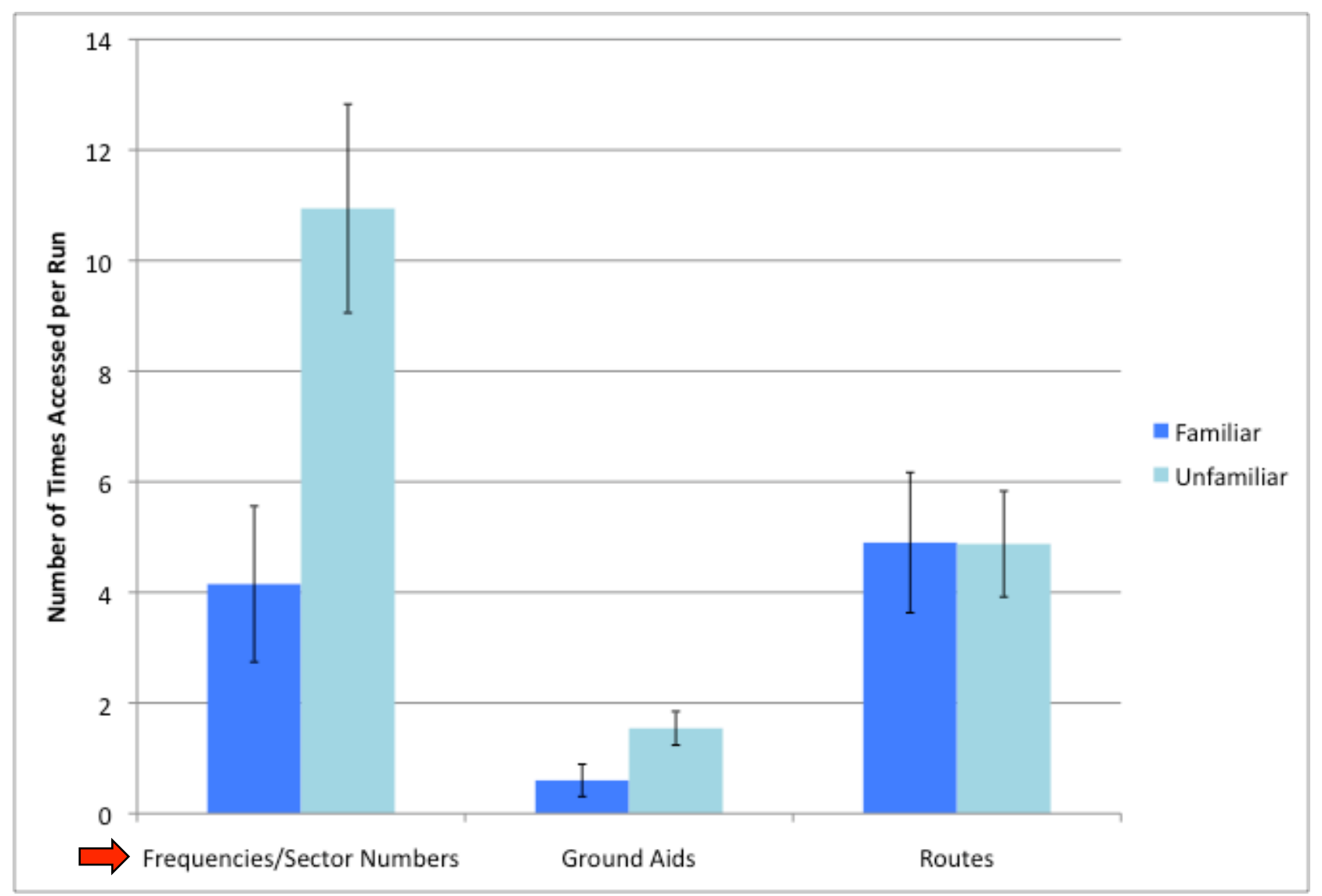

Access to sector data. 


\section{Results}

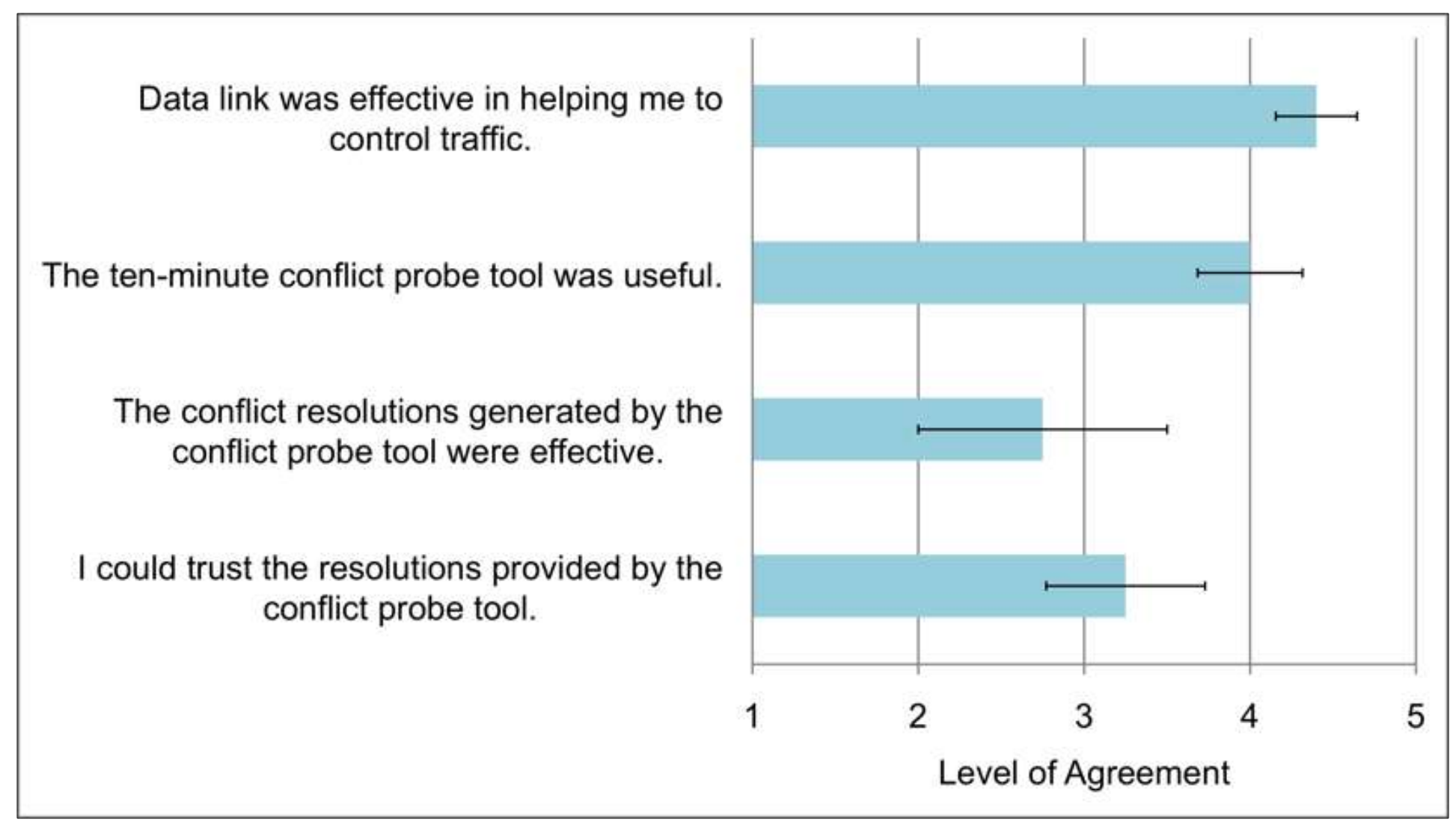

Ratings for NextGen tools. 


\section{Summary}

- Participant comments:

- Supported generic airspace concept

- Larger variety of sectors to work could improve job satisfaction and reduce complacency

- Less familiarity might result in more basic control strategies and reduced service to aircraft

- Some practice on an unfamiliar sector would be helpful prior to working traffic

- Generic sectors may be feasible assuming:

- High altitude, low to moderate complexity airspace

- Important sector data provided to controller

- Mid-term NextGen tools to assist controller and reduce sector information requirements 


\section{Recommendations}

- Conduct further generic airspace research to investigate the robustness of the concept under higher traffic levels

- Explore conditions where there are off-nominal events, such as weather, emergencies, or automation failures

- Consider best location for the sector data

- Add capabilities to the automation environment, including TBO and sector management (e.g., combining/ decombining sectors) 


\title{
Generic Airspace Team (GAT)
}

\author{
Wayne Bridges \\ Rod David \\ Mark Evans \\ Vimmy Gujral \\ Jim Gibson \\ Jim Miller \\ Richard Mogford \\ Dan Peknik \\ Jacob Pfeiffer \\ Bill Preston \\ John Shih \\ Kendrick Wang \\ Forrest West
}

